\title{
Stationary magnetospheric convection on November 24, 1981. 1. A case study of "pressure gradient/minimum-B" auroral arc generation
}

\author{
Y. I. Galperin ${ }^{1}$ and J. M. Bosqued ${ }^{2}$ \\ ${ }^{1}$ Space Research Institute of Russian Academy of Sciences, 117810, Moscow, Russia \\ ${ }^{2}$ Centre d'Etude Spatiale des Rayonnements, CNRS/UPS, 9, Avenue du Colonel Roche-31028 Toulouse Cedex, France
}

Received: 22 January 1998 / Revised: 19 August 1998 / Accepted: 31 August 1998

\begin{abstract}
We present two case studies in the night and evening sides of the auroral oval, based on plasma and field measurements made at low altitudes by the AUREOL-3 satellite, during a long period of stationary magnetospheric convection (SMC) on November 24, 1981. The basic feature of both oval crossings was an evident double oval pattern, including (1) a weak arctype structure at the equatorial edge of the oval/polar edge of the diffuse auroral band, collocated with an upward field-aligned current (FAC) sheet of $\sim 1.0 \mu \mathrm{A}$ $\mathrm{m}^{-2},(2)$ an intermediate region of weaker precipitation within the oval, (3) a more intense auroral band at the polar oval boundary, and (4) polar diffuse auroral zone near the polar cap boundary. These measurements are compared with the published magnetospheric data during this SMC period, accumulated by Yahnin et al. and Sergeev et al., including a semi-empirical radial magnetic field profile $B_{Z}$ in the near-Earth neutral sheet, with a minimum at about $10-14 R_{E}$. Such a radial $B_{Z}$ profile appears to be very similar to that assumed in the "minimum- B/cross-tail line current" model by Galperin et al. (GVZ92) as the "root of the arc", or the arc generic region. This model considers a FAC generator mechanism by Grad-Vasyliunas-Boström-Tverskoy operating in the region of a narrow magnetic field minimum in the near-Earth neutral sheet, together with the concept of ion non-adiabatic scattering in the "wall region". The generated upward FAC branch of the double sheet current structure feeds the steady auroral arc/inverted-V at the equatorial border of the oval. When the semiempirical $B_{Z}$ profile is introduced in the GVZ92 model, a good agreement is found between the modelled current and the measured characteristics of the FACs associated with the equatorial arc. Thus the main predictions of the GVZ92 model concerning the "minimum-B" region are consistent with these data, while some small-scale features are not reproduced. Implications of the GVZ92 model are discussed, particularly concerning
\end{abstract}

Correspondence to: J. M. Bosqued the necessary conditions for a substorm onset that were not fulfilled during the SMC period.

Key words. Magnetospheric physics (auroral phenomena; magnetospheric configuration and dynamics; plasma sheet).

\section{Introduction}

Auroral homogeneous arcs are the typical stationary features of the auroral oval during steady conditions (see Oguti, 1981; Galperin, 1992, 1994). Several different approaches were used to devise a theory of their formation since the very beginning of magnetospheric research (see, Borovsky, 1993 for a critical review). Without considering all these attempts, we mention here only three (not mutually exclusive) which somewhat escaped attention in that review, but are relevant for our observations.

One is that by Tverskoy (1982a, b) which derived, independently from Grad (1964), Vasyliunas (1970) and Boström (1975), but for a more general case of space scales comparable to the ion Larmor radius, the formula for a field-aligned current (FAC) generator (see formula 2 in the Sect. 4.1) which we call the GVBT mechanism. In that theory, a steady auroral arc (or, multiple arcs) is considered as resulting from a specific instability of the magnetosphere-ionosphere system for an upward FAC. It arises due to an increased ion scattering in the plasma sheet, and leads to a decrease of the electric potential at the plasma sheet part of the plasma flux tube, and thus to generation of an upward FAC feeding the arc. A Schrödinger-type equation was derived for the electric potential radial profile along the plasma sheet axis, which can accommodate for a single FAC feeding an arc/inverted- $\mathrm{V}$, and also for multiple FAC sheets feeding several parallel arcs. The region of dipole-to-stretched magnetic field transition in the near-Earth tail, i.e. the 
outer boundary of the radiation belt, was predicted to be the site of the steady arc generation, and to have a width of $\sim 100 \mathrm{~km}$ (Tverskoy, 1982a). It is difficult to directly compare this theory in its present form with measurements, but it obviously deserves a further study and development to be compared with experimental data. These ideas, and in particular the GVBT mechanism of FAC generation, were used in the "minimum- $B$ " model by Galperin et al. (1992) (hereafter, GVZ92) and by Galperin (1992), and are considered here quantitatively though with suitable approximations.

Another theory is that being developed by Samson et al. (1992) (see also, Liu et al., 1995), stimulated by high resolution ground-based optical observations of arcs from the Canadian CANOPUS network. Oscillations and splitting of homogeneous arcs with periods of order of 10-20 min are often observed, basely distinguishable by the naked eye. The theory considers various forms of Alfvén resonance conditions on the respective plasma flux tubes when the energy from the continuum of oscillations feeds a narrow resonance in a shell with a dissipation at the ionospheric foot of a flux tube. But, the respective radial profile at the plasma sheet origin/generator of an arc's plasma flux tube, or shell, apparently was not fully specified yet in this theory, so again direct comparisons with the highaltitude satellite measurements within the plasma sheet are still difficult. Some implications of these observations and concepts in respect to the model described here will be briefly discussed further.

The third approach, which will be followed here and compared with the data, was proposed in GVZ92. It considers the radial magnetic field profile in the inner plasma sheet, or more precisely, in a region of dipole-tostretched magnetic field transition close to the inner edge of the cross-tail current (CTC). The CTC flowing in the dawn-dusk direction presumably maximizes near its inner edge. The CTC leads to a magnetic field $B_{\mathrm{CTC}}$ in opposite direction to the dipole field $B_{D}$, so that the resulting total field is $B_{\mathrm{TOT}}=B_{D}+B_{\mathrm{CTC}}$. If the inner edge of the CTC, at a radial distance $R_{A}$, is sufficiently sharp, and the CTC density decreases sufficiently with distance down the tail, the radial profile of $B_{\text {TOT }}$ will form a narrow minimum close to $R_{A}$. This magnetic field minimum (MFM) presumably occurs at, or close to, the region of strong stochasticity for the plasma sheet ions, where their bounce motion resonates with the Larmor rotation (Büchner and Zelenyi, 1987, 1989). The resulting non-adiabatic westward motion of the ions (while electrons remain magnetized) leads to an additional westward "line current" (WLC) in this direction. A field-aligned current is created along the MFM shell due to an azimuthal divergence of the CTC and WLC. As we shall see the angle between the vectors of the radial pressure gradient $\vec{\nabla}_{X} P$ and gradient of unit magnetic flux $\vec{\nabla} W$ is quite small (of the order of a degree), so it is natural to suppose the proportionality between $\vec{\nabla}_{X} P$ and $\vec{\nabla}_{Y} P$. Thus a similar minimum in the $\vec{\nabla}_{Y} P$ is supposed in this model, which leads to formation of a double sheet FAC profile. Forming of WLC, will modify in turn the total magnetic field radial profile, so that some equilibrium profile is presumed to develop in steady conditions (see a qualitative discussion of this point in Galperin, 1992). However, a self-consistent description of this region is still lacking, though some efforts to develop it are continuing (see, Peroomian et al., 1997).

The importance of a local enhancement of the CTC due to the non-adiabatic motion of ions at its inner edge, which was earlier suggested in GVZ92, was then demonstrated by a large-scale kinetic model (LSK) of particle trajectories (Ashour-Abdalla et al., 1992a, b, 1993, 1994; Bosqued et al., 1994). The non-adiabatic ion motions form a narrow "wall region" defined by Ashour-Abdalla et al. (1994). LSK simulations in 3D (Bosqued et al., 1994) demonstrated the formation of strong radial and azimuthal plasma pressure gradients in the dusk-midnight region where the magnetic field gradients are the strongest. Using the current closure relationship they were able to compute the net FAC density mapped down to the ionosphere. Two prominent regions of upward FACs appeared, (1) around $65^{\circ}$ ILAT at midnight which must give rise to the equatorward-most auroral arc of the oval, and (2) a poleward oval arc around $72-76^{\circ}$ ILAT, in good qualitative agreement with observations. The LSK approach, and model calculations, is a way potentially synthesizing the theories described already in a direct quantitative manner, but much work is still to be done to achieve the needed representation of the natural processes.

An important aspect of the simplified analytical approach in GVZ92 is its direct relation to the problem of the substorm onset. Under certain conditions (increase of the CTC, and/or sharpening of its earthward edge or, its radial gradient), the magnetic field $B_{\mathrm{TOT}}$ within the MFM could reach low values sufficient for the plasma sheet electron demagnetization, or even reach zero, or reverse its $B_{Z}$ direction. This kind of evolution of the MFM was suggested in GVZ92 as the probable cause for the substorm onset. According to GVZ92 a largescale CTC instability leading to a substorm onset must occur: (1) in the region of the MFM, (2) after a $B_{Z}$ decrease related to an increase of the CTC and, (3) at, or close to, the magnetic shell of the equatorward-most auroral arc. The last two predictions from GVZ92 are consistent with observations (see, Akasofu 1964 for the substorm onset location in respect to the auroral arc, and Baker et al. (1993) for a decrease of the magnetic field in the neutral sheet leading to electron demagnetization just before the onset), while the first one seems new. The extension of the GVZ92 model for a substorm onset, or a smaller scale auroral activation, is considered in Galperin and Bosqued (1998) and Galperin (1998).

A specific virtue of the GVZ92 analytic model is to propose an explicit relation, testable by measurements in the plasma sheet, between the magnetic field radial profile $B_{Z}$ along the near-Earth neutral sheet, and the implied profile of the field-aligned sheet currents presumably feeding the auroral arc/inverted-V auroral structure. However to find a suitable experimental data set is not easy, because the radial profiles of the magnetic field $B_{Z}$, and of the integral sheet current 
density $J_{\perp}$, cannot be measured directly along a single satellite orbit, and thus awaits the CLUSTER mission.

An important exception from these experimental difficulties is provided by a unique set of various magnetospheric data collected by Yahnin et al. (1994) (Y94) and Sergeev et al. (1994, 1996, later SPP96) for a long and stable stationary magnetospheric convection (SMC) interval on November 24, 1981. It includes a southern premidnight $(840 \mathrm{~S})$ and a northern dusk (840N1) auroral oval crossing by the low-altitude polar orbiting AUREOL-3 satellite (hereafter A3) during that day; the preceding dayside crossing of the cusp region $(840 \mathrm{~N})$ is discussed in the companion paper (Galperin et al., 1999). The present study will describe observations made by $\mathrm{A} 3$ on two passes, $840 \mathrm{~N} 1$ and $840 \mathrm{~S}$, together with other data collected during this SMC interval and, then, will compare them with the predictions of the GVZ92 model of auroral arc/inverted-V generation.

The work is organized as follows. In Sect. 2 the onboard instrumentation (particles, field-aligned currents, electron density and temperature) will be summarized. The data collected on the consecutive eveningside and nightside auroral passes are presented in Sect. 3; we shall show that the electron intensity distribution across the auroral oval as measured by A3 resembles that of the double oval observed by satellite UV imagers (Elphinstone et al., 1995a, b) and, for the SMC period under study, by the DE-1 satellite. This set of A3 data will be used in the following parts for comparisons with the results of the arc/inverted-V model GVZ92 summarized in Sect. 4; at that point we shall introduce different radial $B_{Z}$ profiles in the near-Earth tail and compute the observed shape and intensity of the FACs at ionospheric level. In Sect. 5 we shall discuss the characteristics of the double oval observed during the SMC period and its mapping to the plasma sheet. We shall show that this double oval maps to the whole extended plasma sheet from its inner edge to the far distant tail $\left(100 \pm 50 R_{E}\right)$. Finally we shall try to answer to the question: why substorms onsets did not occur during the IMF- $B_{Z}<0$ conditions prevailing during that prolonged period?

\section{Instrumentation}

The A3 satellite set up for magnetosphere-ionosphere interaction studies was a 3-axis gravity-gradient stabilized low-altitude (400 to $2000 \mathrm{~km}$, inclination $82^{\circ}$ ) spacecraft launched from Plesetsk, Russia on September, 21, 1981 under the aegis of the Soviet-French space cooperation. The full description of the satellite and scientific payload, together with the first results obtained, are presented in a special issue of Annales de Géophysique (38, N 5, 1982). The data used in this study came from the following onboard instruments: the 4channel electrostatic particle detector RIEP-2802 (Galperin et al., 1982), in the fixed-energy mode at $100 \mathrm{eV}$ and $1.8 \mathrm{keV}$ both for electrons and ions; the multidirectional electrostatic analyzer SPECTRO/ROT for electrons and ions from 0.2 to $22 \mathrm{keV}$ (Bosqued et al., 1982); a standard onboard magnetometer aimed to the attitude restitution whose output was digitized and extended by the onboard TRAC device (Berthelier et al., 1982); and the mutual impedance interferometric double probe ISOPROBE for electron density and temperature measurements (Béghin et al., 1982).

The measurements for pass $840 \mathrm{~S}$, discussed later were made by direct transmission to ground-based telemetry station in Terre-Adélie, Antarctica. The pass 840N1 across the dusk oval, discussed later, and the pass $840 \mathrm{~N}$ across the cusp (discussed in accompanying study Galperin et al., 1998) were recorded in memory mode with readout by Soviet telemetry stations. The data processing was made both at the Space Research Institute (IKI), Moscow, and in CNES and CESR, Toulouse.

\section{Observations}

Figure 1, adapted from Yahnin et al. (1994), displays the time dependence of the IMF components, and $A E$, $A U, A L$ auroral indices, relevant for the SMC period of November 24, 1981. The times of the A3 crossings along orbit 840 , first of the northern dayside cusp and mantle regions (0738-0743 UT), second of the eveningside northern oval (0750-0800 UT, later in the text, pass $840 \mathrm{~N} 1$ ), and, finally, of the nightside auroral oval ( 0835-0837 UT, later in the text, pass $840 \mathrm{~S})$ are marked by vertical lines. Here we present and analyze the data collected on the consecutive eveningside and nightside auroral passes in order to insert them in the

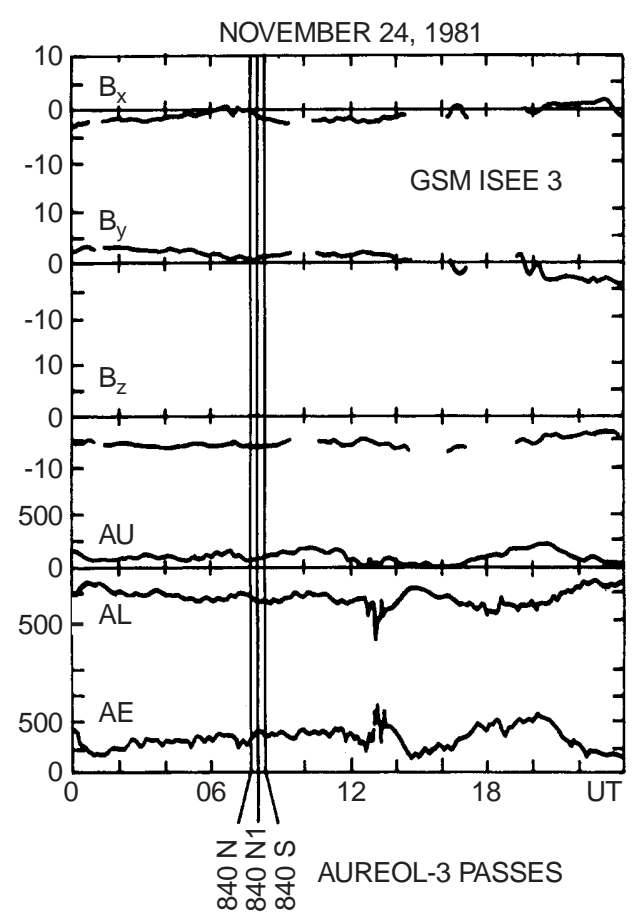

Fig. 1. Activity on November 24, 1981. From top to bottom: GSM components of the IMF measured by the ISEE-3 satellite; auroral electrojet indices, AU, AL, AE. The 3 AUREOL-3 passes relevant for this SMC study are indicated by vertical lines. (adapted from Yahnin et al., 1994) 
more global context of magnetospheric data collected during that long SMC time period, already presented by Y94 and SPP96.

\subsection{Premidnight sector}

Figure 2 gives the electron and proton (ion) energy-time spectrograms at $\sim 10^{\circ}$ pitch angle, obtained during the nightside southern pass $840 \mathrm{~S}$ at altitudes from $\sim 1500$ to $\sim 1300 \mathrm{~km}$. In Fig. $3 \mathrm{a}$ we present: all the $D B_{y}$ and $D B_{x}$ components of the magnetic field variations (approximately along and perpendicularly to the auroral oval direction; smoothed magnetic field components interpolated between the sides of the oval with account of the s/ c attitude were subtracted), the $1.8 \mathrm{keV}$ and $100 \mathrm{eV}$ fixed-energy electron intensity profiles, (Fig. 3b) the proton flux profiles at $1.8 \mathrm{keV}$ and $100 \mathrm{eV}$, (Fig. 3c) the thermal electron density and temperature. (Fig. 3d)

The electron spectrogram (Fig. 2) displays a typical sequence of particle spectra and intensities during a steady oval crossing (see, for example, Feldstein and Galperin, 1985; Newell et al., 1996). Towards the pole, a boundary of diffuse auroral precipitation is first crossed at 0833:25-30 UT (1.8 keV electron channel, RIEP high sensitivity spectrometer, see Fig. 3b); the diffuse region extents up to $\sim 0835: 18 \mathrm{UT}$; the average energy flux measured by the SPECTRO/ROT instrument was $4.2 \mathrm{ergs}\left(\mathrm{cm}^{2} \mathrm{sr} \mathrm{s}\right)^{-1}$. Then, as evidenced by the $100 \mathrm{eV}$ electron profile (Fig. 3b), a weak (multiple) auroral arctype structure is crossed between 0835:18.4 and 0835:24.5 UT (ILAT 63.7-63.9, MLT 22.0). It coincides with a well-defined upward field-aligned current band $\left(\mathrm{d}\left(D B_{y}\right) / \mathrm{d} t>0\right)$ carrying a current density of $1.0 \mu \mathrm{A} \mathrm{m}^{-2}$ averaged for the band (Fig. 3a, vertical grey band). An expanded view of the $100 \mathrm{eV}$ electron flux profile across the arc-like structure is shown in Fig. 4 on the top panel. It consists of several narrow maxima (some of them of $\Delta t \leq 200 \mathrm{~ms}$, i.e. of a $1.5 \mathrm{~km}$ scale thickness or less) with two much more intense than the others at 0835:23-0835:25 UT. It must be noted that the maximum counting rates of the RIEP-2802 detector in the narrow intense arcs/filaments are near the level of saturation, so that these electron spikes are indeed even stronger in time/space. There the energy flux reached 4.8 ergs $\left(\mathrm{cm}^{2} \mathrm{sr} \mathrm{s}^{-1}\right.$ from SPECTRO/ROT data. While the $1.8 \mathrm{keV}$ electron precipitation (Fig. 3b) stays rather intense but structureless in this region, the ROT electron spectrogram shows locally enhanced electron intensities centred at 0835:24 UT, with rather flat (or a Kappatype) energy spectra not typical for an inverted- $\mathrm{V}$, and extended to more than $10 \mathrm{keV}$ (Fig. 4, bottom panels).

Concerning the ion precipitation in the discrete auroral region (mostly protons, as seen from the data of the ION mass-analyzer, not shown), successive and narrow intensity spikes at $100 \mathrm{eV}$ are detected between $\sim 0835: 10$ and 0835:30 UT (Fig. 3c), i.e. equatorward, and superimposed onto, the equatorial electron arc/ inverted-V described already. At $1.8 \mathrm{keV}$ an intensity maximum is clearly evident at $\sim 0835: 40$ UT, a little poleward from the electron arc. It is interesting to note that if the ion $1.8 \mathrm{keV}$ intensity profile in this region is shifted equatorward by $\sim 20$ s (i.e. $\sim 1.24^{\circ}$ in ILAT), it looks rather similar to the $100 \mathrm{eV}$ ion latitudinal profile. In the discussion we shall compare the locations of the two ion intensity maxima in Fig. 3c with the concept of stochastic ion scattering in the neutral sheet for the respective energies (thick arrows).

Coming back to the electron spectrogram (Fig. 2) and, more precisely, to the central part of the wide

AUREOL-3 24 NOV 1981 ORBIT: 840-4 MODE: 514 SEQ: 416

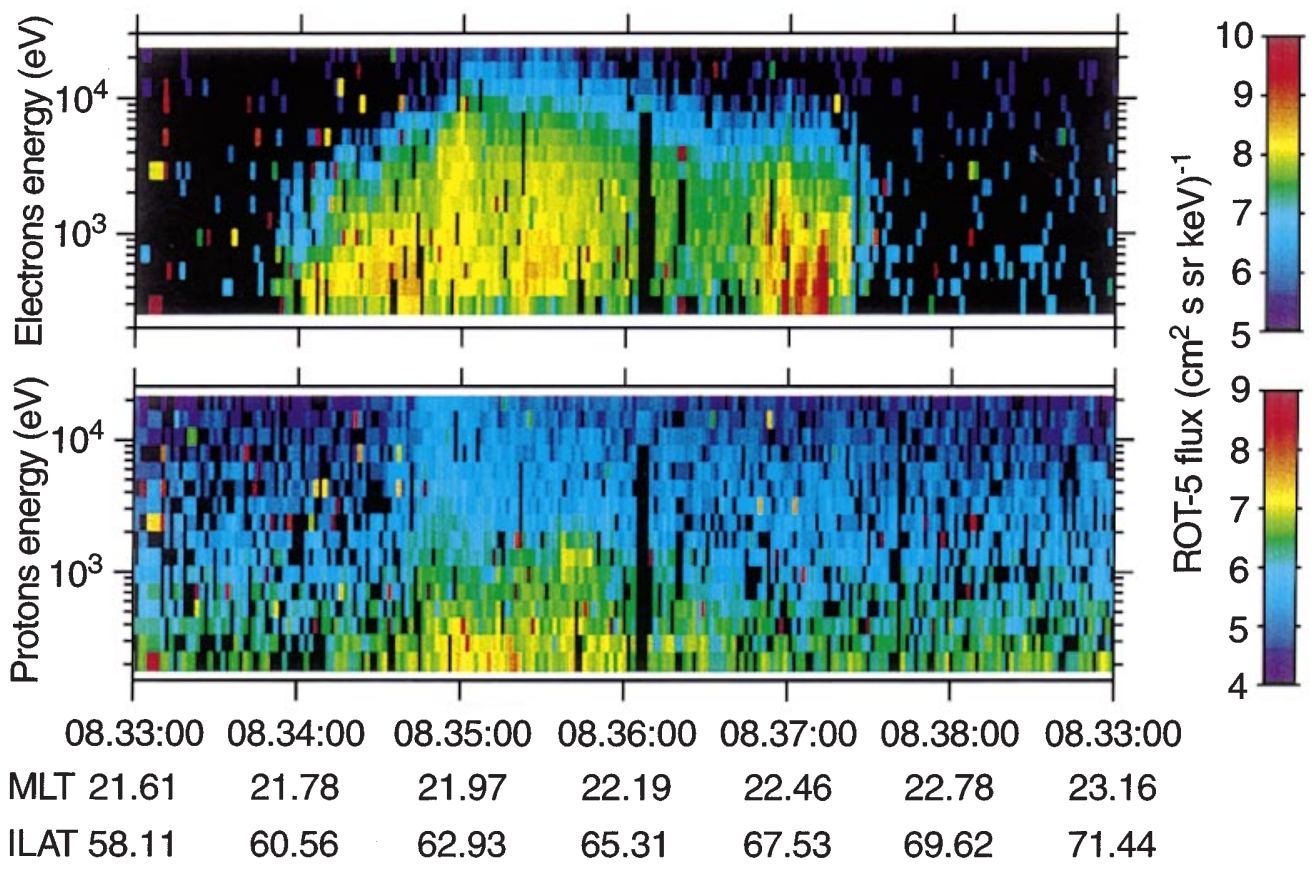

Fig. 2. AUREOL-3 electron and ion (proton) differential flux spectrograms from $\sim 200 \mathrm{eV}$ to $\sim 22 \mathrm{keV}$, during the southern pass $840 \mathrm{~S}$ over Antarctica on Nov. 24, 1981 around 0835 UT (altitude: $\sim 1300 \mathrm{~km}$ ), measured by the SPECTRO/ROT_5 sensor (pitch angle: $\sim 30^{\circ}$ ). Differential fluxes are expressed in $\left(\mathrm{cm}^{2} \mathrm{~s} \mathrm{sr}\right.$ $\mathrm{keV})^{-1}$ units 


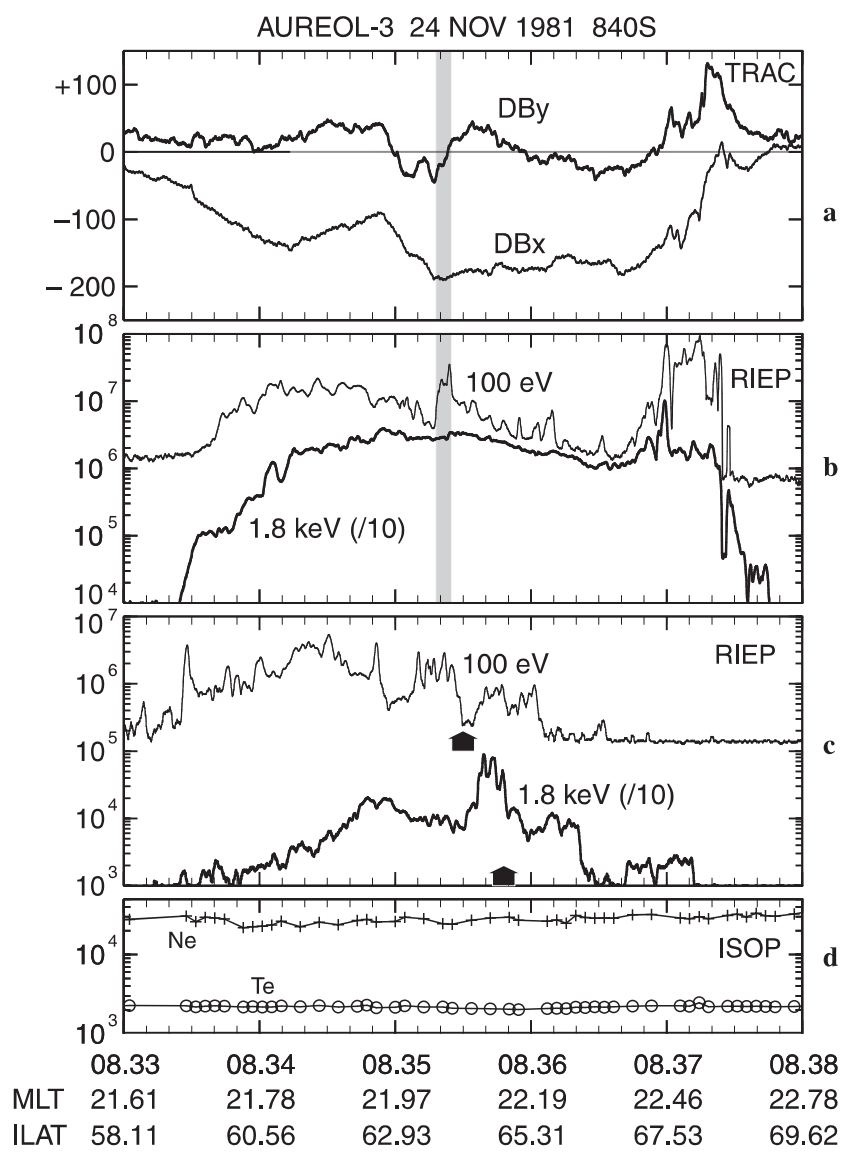

Fig. 3a-d. A3 measurements during pass 840S: a $D B_{x}$ and $D B_{y}$ variations (nT) of the horizontal magnetic field measured by the TRAC magnetometer, after subtraction of the background magnetic field ( $D B_{x}$ along the orbital direction, $D B_{y}$ perpendicular to it, sampling rate: $80 \mathrm{~ms}$, running averages on $1.2 \mathrm{~s}$ ); b electron differential fluxes $\left(\mathrm{cm}^{2} \mathrm{~s} \text { sr } \mathrm{keV}\right)^{-1}$ at 2 fixed energies, $100 \mathrm{eV}$ and $1.8 \mathrm{keV}$ (bold curve, flux divided by 10), given by the RIEP spectrometer (pitch angle: $\sim 50^{\circ}$; sampling rate: $80 \mathrm{~ms}$; running averages on $1.2 \mathrm{~s}$ ); $\mathbf{c}$ proton differential fluxes at 100 and $1.8 \mathrm{keV}$ (bold curve, flux divided by 10); d electron density $N_{e}\left(\mathrm{~cm}^{-3}\right)$ and temperature $T_{e}\left({ }^{\circ} \mathrm{K}\right)$ measured by the ISOPROBE instrument (same scale). The region of the weak auroral arc is indicated in $\mathbf{a}$ and $\mathbf{b}$ by a vertical grey band. See text for vertical arrows in panel $\mathbf{c}$

auroral oval, it is seen that, poleward of the already described equatorial arc/inverted-V structure, lies a region of depressed electron precipitation of $\leq 1 \mathrm{keV}$. It is extended from $\sim 0836: 10$ (ILAT $=65.5$ ) to $0836: 45$ UT (ILAT $=67.3)$, as is well shown by a minimum in the $100 \mathrm{eV}$ electron intensity profile (Fig. 3b), but less significant at $1.8 \mathrm{keV}$. Appreciable, though depressed, ion intensities in the keV energy range are seen in Fig. 2 throughout this region of the electron intensity depression forming the "double oval" structure.

Moving poleward, another very intense band of highly structured electron precipitation is clearly visible on the spectrogram (Fig. 2) at $\sim 0836: 50-0837: 30$ UT (ILAT $\sim 67.2-68.6$, MLT $~ 22.4-22.6$ ); it is evident as well in the $100 \mathrm{eV}$ as in $1.8 \mathrm{keV}$ electron flux profiles (Fig. 3b). This intensive band constitutes the polar edge of the auroral oval of discrete forms, and is coincident with the band of strong $\left(\sim 3.3 \mu \mathrm{A} \mathrm{m}^{-2}\right)$ upward current.
AUREOL-3 24 NOV 1981 ORBIT: 840S
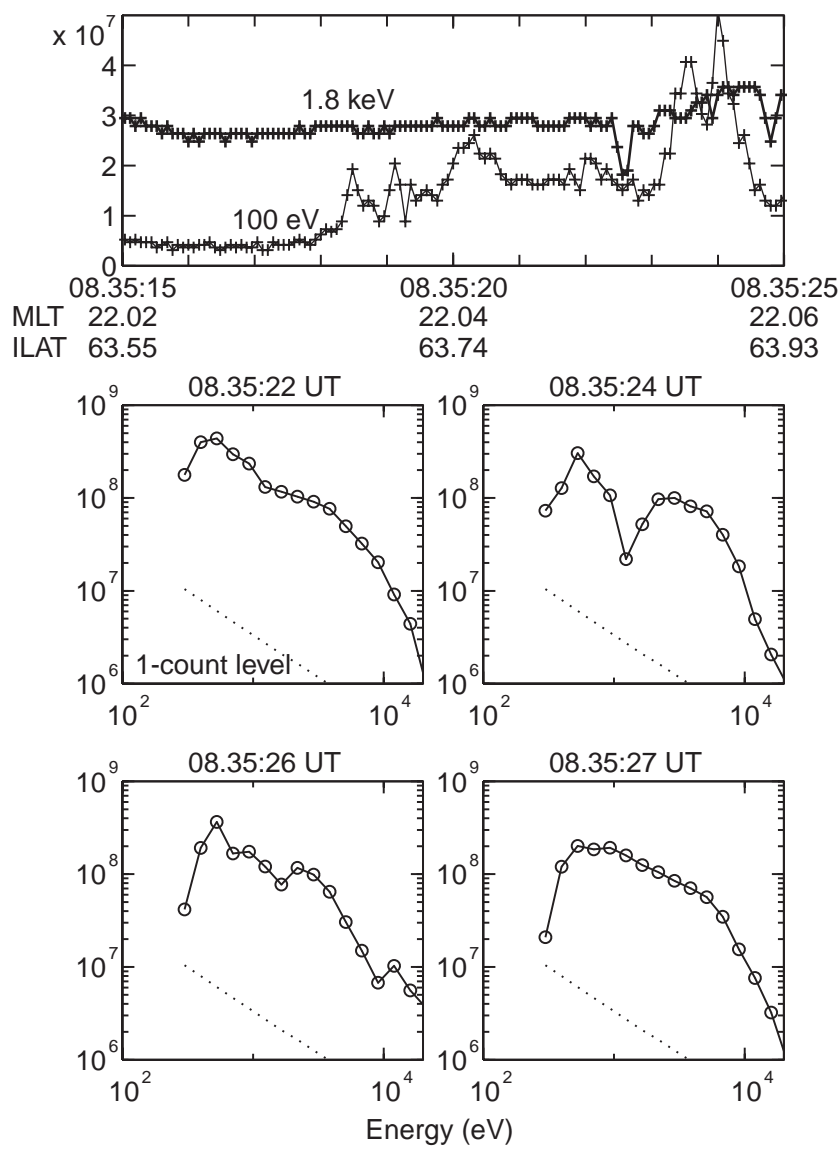

Fig. 4. Electron precipitation in the auroral arc detected between 0835:18 and 0835:25 UT. Top: expanded view of the electron fluxes at $100 \mathrm{eV}$ (light curve) and $1.8 \mathrm{keV}$ (bold curve) measured by the RIEP instrument; middle and bottom: four successive electron differential spectra measured by the ROT_5 sensor, starting at 0835:22 UT. Differential fluxes are expressed in $\left(\mathrm{cm}^{2} \mathrm{~s} \mathrm{sr} \mathrm{keV}\right)^{-1}$ units and the 1count level for the ROT sensor is indicated in each panel by a dotted line

Further poleward from this intensive band, till the polar cap boundary, there is a narrow region of weak diffuse electron precipitation, the polar diffuse auroral zone. Although the $1.8 \mathrm{keV}$ ion flux remains very low during this time, its comparison with the ROBE spectral data suggest that it could be the signature of a polar velocitydispersed ion structure (VDIS-2) (Bosqued, 1987; Kovrazhkin et al., 1987; Zelenyi et al., 1990; Saito et al., 1992; Bosqued et al., 1993). However, it is not identifiable by the onboard ROBE spectrometer data (Bosqued et al., 1982) due to its low intensity, $\leq 10^{5}$ ions $/\left(\mathrm{cm}^{2}\right.$ s sr keV).

The A3 data on DC electric fields across the equatorial arc/inverted-V (not shown) do not display a significant flow shear. This is consistent with the implied absence of a significant integral conductivity gradient at the arc.

To summarize this data presentation, the whole electron intensity distribution across the nightside auroral oval, as observed by the A3 satellite during pass $840 \mathrm{~S}$, resembles that of the double oval observed by satellite UV imagers (Elphinstone et al., 1995a, b). 
However, the $1.8 \mathrm{keV}$ electron profile obtained by the high time resolution RIEP spectrometers as well as the ROBE data reveal that the "gap" in precipitation intensity between the equatorward and poleward bands is not very significant at that energy. However, the total energy flux (which includes prominent $5-10 \mathrm{keV}$ electrons and thus is directly proportional to the auroral brightness) is indeed significantly depressed in between the equatorial auroral region and the bright polar band. This double oval structure is well confirmed by the global auroral images from the DE-1 satellite already presented in Y94 (their Fig. 7). But the steady auroral arc at the polar edge of the diffuse auroral band was not noted in Y94 (see discussion of possible reasons for this lack of the arc detection in Sect. 5.1). We may notice that in the data presented in Y94 and SPP96, the thresholds for the plotted auroral brightness and for the imagery data were apparently setup at $\sim 1 \mathrm{kR}$, so that the depression could appear deeper than it really was.

\subsection{Evening sector}

Before the premidnight (southern) oval crossing 840S described in the previous section, on the same orbit 840 A3 made measurements in the Northern Hemisphere. Initially it crossed the cusp region and these data, (pass $840 \mathrm{~N}$ ) are described in the companion study by Galperin et al. (1999). Then it passed over the polar cap, and then successively through the northern eveningside auroral oval, the diffuse auroral zone, and the ionospheric main trough (pass $840 \mathrm{~N} 1$ ), and these data will be considered here. The data recording on the pass $840 \mathrm{~N} 1$ was in a slow memory mode, so particle data only from RIEP2802 are available.

As shown in Fig. 5, the polar and equatorial boundaries of the eveningside oval (i.e. the region of structured electron precipitation) are respectively crossed on 0747:25 (ILAT $\sim 71.2$ ) and 0750:10 UT (ILAT $\sim 65.3$, MLT 17.8) as may be deduced using only the RIEP2802 data. From these data it seems that an intense arc/ inverted-V was present near the sharp polar boundary of the oval, at $\sim 0747: 40$ UT $($ ILAT $=71.3$, MLT $=$ 16.9). Moving equatorward, the total electron energy flux decreased and then, a series of arc/inverted-V structures, between $\sim 0748: 55$ UT and $\sim 0749: 50$ UT, was crossed on the trajectory oblique to the oval. Then at the equatorial boundary of the oval, a weak arc/ inverted-V of $100 \mathrm{eV}$ electrons only was crossed at $\sim 0749: 57-0750: 08$ UT (ILAT $=65.4$, MLT $=17.8$ ), near the polar edge of the diffuse auroral zone. This lowintensity equatorial arc of the oval is collocated with an upward current of about $1 \mu \mathrm{A} \mathrm{m}^{-2}$ (Fig. 5a, vertical grey stripe), and is not detectable in the $1.8 \mathrm{keV}$ electron flux channel (Fig. 5b). Finally, the equatorial edge of diffuse auroral precipitation, called the soft electron precipitation boundary (SEB), is crossed around 0750:35 UT $($ ILAT $=64.3$, MLT $=17.9)$. It can be noted that in this dusk sector the $100 \mathrm{eV}$ low-energy ion precipitation extends to much lower latitudes than the
AUREOL-3 24 NOV 1981 840_N1

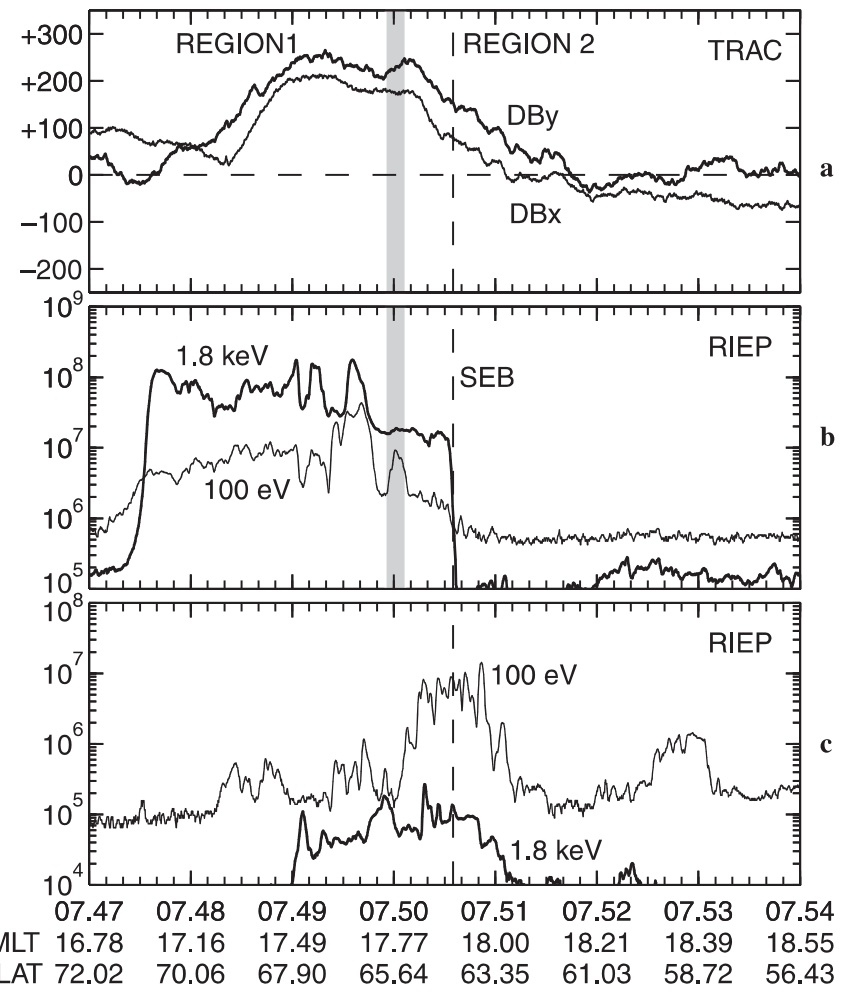

Fig. 5a-c. Pass $840 \mathrm{~N} 1$, from top to bottom: a $D B_{x}$ and $D B_{y}$ variations of the horizontal magnetic field (TRAC magnetometer); $\mathbf{b}$ electron differential fluxes at 2 fixed energies, $100 \mathrm{eV}$ and $1.8 \mathrm{keV}$ (RIEP spectrometer); $\mathbf{c}$ proton differential fluxes at 100 and $1.8 \mathrm{keV}$. The sampling rate for the TRAC and RIEP instruments is $320 \mathrm{~ms}$, and running averages on $1.6 \mathrm{~s}$ are plotted in the three panels. The auroral arc is indicated by a vertical grey band, and the SEB boundary is referenced by a vertical dashed line (see text for details)

SEB boundary, down to about 0753:05 UT $($ ILAT $\sim 58.5)$.

On a large-scale, the FAC structure displayed in Fig. 5a was of the classical region I/region II type for the eveningside auroral oval. Sequentially, (a) on its polar side, a wide upward FAC band of about $1.2 \mu \mathrm{A} \mathrm{m} \mathrm{m}^{-2}$ extended from the polar edge of the polar arc/inverted-V till the middle of the oval ( 0749:00 UT); then (b) till $\sim 0749: 50$ UT the large-scale FAC was lower than our sensitivity threshold; then (c) a narrow band of FAC of $\sim 1 \mu \mathrm{A} \mathrm{m}^{-2}$ was crossed which is collocated with a weak low-energy arc/inverted- $\mathrm{V}$; and (d) after that a largescale downward FAC band (region II) was crossed which extended from the equatorial oval arc at $\sim 0750: 10$ UT to $\sim 0752$ UT (ILAT $=61.0$, MLT $=$ 18.2).

Electron density measurements from the ISOPROBE instrument, for this pass in the passive mode (not shown), give densities of about $2-3 \times 10^{4} \mathrm{~cm}^{-3}$ above the evening auroral oval and diffuse auroral zone at altitudes of $1300-1600 \mathrm{~km}$. It is known that at these altitudes the main trough is not easily distinguishable in the electron density data. As mentioned, the SEB was crossed at 0750:35 UT (ILAT $=64.3$, MLT $=17.9)$.

It must be noted that the overall latitudinal profile in the dusk sector is qualitatively very similar to that in the 
premidnight sector described in the previous section. In particular, a weak arc collocated with an upward FAC of $\sim 1.0 \mu \mathrm{A} \mathrm{m}^{-2}$ at the oval equatorial boundary resembles that at the nightside and suggests that it was the same feature extended all along the oval boundary at least in the evening-premidnight sectors. However, the adjacent narrow downward FAC here was poleward from the arc, while in the premidnight sector it was equatorward. At the same time, the diffuse auroral band at dusk was narrower than in the premidnight sector, while the low-energy ion precipitation extended well equatorward beyond the SEB which was not the case on the nightside pass $840 \mathrm{~S}$.

\subsection{Comparison with other data}

Here we compare these A3 results with the available data from other low-altitude satellites and ground-based measurements during this SMC period.

The location of the polar cap boundary crossing by the A3 satellite in the dusk sector, as well as the location of the polar edge of the diffuse auroral zone at its equatorial side, are in good agreement with the simultaneous DE-1 data images published in Y94. These images indicate that the global oval structure was rather stable in time, continuous and extended from the evening to premidnight sector, and even further in the post-midnight and morning sectors. However, as mentioned previously, the equatorial arc of the oval was not identified in these images in Y94.

The A3 data in the evening sector considered already can be also compared with the DE-2 electric and magnetic field measurements. The DE-2 satellite crossed the evening oval on the same day, on 0815-0818 UT, i.e. only 25-28 minutes later than A3 and in the same MLT sector. Magnetic field data (Fig. 6, top panel, $D B_{x}$ and $D B_{z}$ components, and the zoom of the $D B_{z}$ component in the middle panel) show an upward FAC band of $\sim 1.0 \mu \mathrm{A} \mathrm{m}^{-2}$ with a latitudinal width of $\sim 50 \mathrm{~km}$ at ILAT $=66.7-66.1$, MLT $=17.9$, presumably the stable arc. (It is to be compared with $\sim 1 \mu \mathrm{A} \mathrm{m}^{-2}$, ILAT $=65.4$ and MLT $=17.8$ for the neighbouring A3 arc crossing). A characteristic electric field spike in the $E_{x}$ and $E_{y}$ components (Fig. 6, bottom panel) is collocated with a narrow downward current of comparable magnitude adjacent from its polar side to the narrow upward current band. At the polar side of the oval a wider $(\sim 80 \mathrm{~km})$ band of upward current of $\sim 3 \mu \mathrm{A} \mathrm{m}^{-2}$ is seen around ILAT $=68.2$ and MLT $=17.8$. It is a really good agreement for the narrow upward current bands/stable auroral bands positions and FAC densities on both sides of the oval from the two satellites. The same arc-like feature at the equatorial edge of the region I current may be also seen on the preceding DE-2 passes (not shown). This confirms that this weak FAC structure was indeed a time-stable one, and the whole structure was similar at least throughout the evening-premidnight MLT sector. The latitude of the region II current equatorial edge
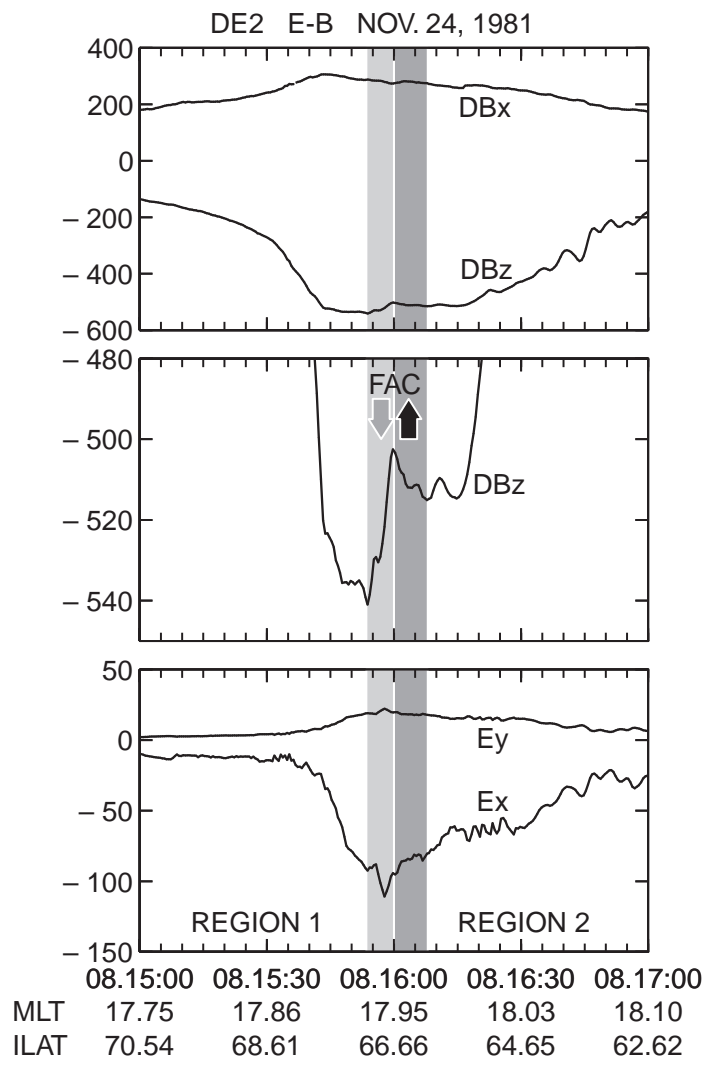

Fig. 6. DE-2 pass on November 24, 1981 at 0815-0817 UT: $D B_{x}$ (southward) and $D B_{z}$ (westward) components of the horizontal magnetic field perturbation in spacecraft coordinates (top); zoom of the westward component $D B_{z}$ (middle) horizontal components $E_{x}$ and $E_{y}$ of the electric field (bottom). (Courtesy J. King, NSSDC, through NASA/NSSDC CDROM "DE-2 E\&B" data). Between 0815:54 and 0816:07 UT the regions of upward FAC (presumably, an arc) and of adjacent downward FAC are shaded differently

from the DE-2 data was also similar to that indicated from the A3 measurements.

Narrow bumps $\sim 1-2$ ergs $\left(\mathrm{cm}^{2} \mathrm{sr} \mathrm{s}\right)^{-1}$ in the lowenergy electron total energy flux at the polar border of the diffuse auroral zone are also seen from the NOAA 7 data presented in Y94 (their Fig. 10) for the postmidnight and morning sectors during this same SMC period. They may be extensions of the same weak auroral arc to these sectors.

The SEB location at nightside and evening sectors is usually collocated with the large-scale convection boundary (Galperin et al., 1977, 1997). It can be compared with the simultaneous data from the DE-2 electric field measurements cited already. As seen from Fig. 6 (bottom panel), the module of electric field $E_{X}$ component significantly decreases in magnitude at $\sim 63.6$ $\leq$ ILAT $\leq 64.6$, then becomes rather small and irregular down to $\sim 62.5$, and then nearly stabilizes at a rather low level. As is seen, the large-scale convection electric field magnitude from the DE-2 data indeed decreases rather close to the location of the SEB boundary determined from the A3 data (ILAT $=64.3$, MLT $=17.9)$, taking into account the $27 \mathrm{~min}$ difference between measurements by the two satellites. 
Another check of the location of the large-scale convection boundary can be made using the longitudinal chain of ionosondes in northern Russia, at nearly the same ILAT values of about $65-66^{\circ} \mathrm{N}$. According to Sivtseva et al. (1989), during the SMC on 24 November, 1981, due to the Earth's rotation, these stations sequentially entered a relatively stable sharp equatorial boundary of the ionospheric main trough at MLT 16.0. Poleward from this boundary, the F-region electron density was significantly lower and strongly inhomogeneous, which is characteristic for a fast convection zone in the postnoon-dusk sector during enhanced activity. So the location of the equatorial edge of the fast convection zone from these ground-based data can be taken at ILAT $\sim 65.5$ at MLT $\sim 16 \mathrm{~h}$ (Sivtseva et al., 1989). This is close to the ILAT $=64.3$ of the SEB at MLT $\sim 17.9 \mathrm{H}$ indicated already from the A3 data. These ionospheric observations again confirm the overall time/space stability of the large-scale convection pattern during the SMC period.

\subsection{Summary of observational data}

Thus we can conclude that the premidnight oval structure, as observed from A3 on pass $840 \mathrm{~S}$, was qualitatively similar to that observed in the eveningside oval on the pass $840 \mathrm{~N} 1$ about $50 \mathrm{~min}$ earlier, and on the DE-2 pass about 20 min earlier. It is also consistent with the global auroral images from the DE-1 satellite taken at the same time. It was a stable double oval structure with: (1) a low-energy arc/inverted-V present at the polar edge of the intense diffuse auroral band delineating the equatorial boundary of the oval of discrete forms, (2) the wide oval of multiple discrete forms including an intensity depression in the middle oval, and (3) an intense structured auroral band at the polar oval boundary. However, the weak auroral arc-like structure which is the subject of this work was not distinguished from the diffuse aurora neither from the DE-1 images, nor from ground-based data.

This set of the A3 data significantly complements the more general framework of the SMC period on November 24, 1981 already presented in Y94 and SPP96. It will be used in following sections for comparisons with the results of the arc/inverted-V model GVZ92, together with the concept of the nonadiabatic ion scattering at the inner edge of the plasma sheet.

\section{Modelling of the FAC density profile}

\subsection{On the "minimum-B" model and its justification}

The "minimum- $B$ " model as described in GVZ92 (see Introduction), in brief, is based on the following. The key point is the radial magnetic field profile along the neutral sheet (expressed as the $r_{0}$ coordinate) with a narrow minimum at about $r_{0} \sim 10 R_{E}$ (Fig. 7). The minimum in the magnetic field $B$ profile (or a negative

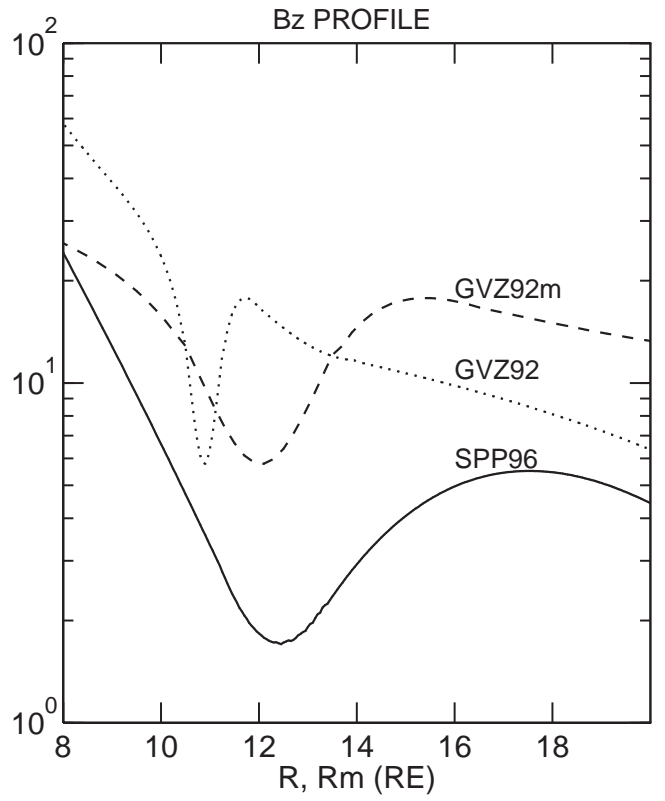

Fig. 7. Various radial $B_{z}$ magnetic field profiles in the near-Earth (8$20 R_{E}$ ) neutral sheet used to model and map the field-aligned currents down to the ionosphere: GVZ92 profile (dotted line): the hypothetical profile used in Galperin et al. (1992); SPP96 (solid line): the semiempirical profile, from Sergeev et al. (1996); GVZ92m (dashed line): GVZ92 profile shifted and extended in tailward direction. (see Sect. 4.1.2 for details)

gradient in the tailward direction) occurs at the supposed near-Earth's edge of the linear density $j_{\perp}$ of the cross-tail integrated sheet current (CTC) which decreases further tailward. Based only on physical considerations, the radial profile of the integrated cross-tail linear current density, $j_{\perp}\left(r_{0}\right)$ was freely chosen in the GVZ92 model, and its corresponding magnetic field $\boldsymbol{B}_{\mathrm{CTC}}\left(r_{0}\right)$ was calculated. The radial profile of the total magnetic field in the neutral sheet $B_{Z}\left(r_{0}\right)$ was obtained by adding the dipole magnetic field component $B_{D}\left(r_{0}\right)$ :

$B_{Z}\left(r_{0}\right)=B_{D}\left(r_{0}\right)+B_{\mathrm{CTC}}\left(r_{0}\right)=B_{D}\left(r_{0}\right)+\int_{r 1}^{r 2} \frac{J_{\perp}(r) \mathrm{d} r}{r_{0}-r}$

The isotropic plasma pressure radial profile was deduced from the supposed pressure equilibrium in the $Z$ direction (or, from the tail approximation when the magnetic tension $(\vec{B} \cdot \vec{\nabla}) \vec{B}$ is negligible). In this case a pressure maximum (only its gradient enters the model) supposedly appears at, or close to, the location of the MFM in the neutral sheet to maintain the force balance in the Z-direction. The FAC density $j_{\|}^{m}$, at the exit from the plasmasheet source region to an auroral arc system in one hemisphere, can be described by the well known GVBT relation (see, for a detailed derivation and analysis, Heinemann, 1990, Heinemann and Pontius, 1991):

$j_{\|}^{m} \frac{1}{2}[\vec{\nabla} W \times \vec{\nabla} P] \quad$ where $W=\int_{0}^{l\left(B_{Z}\right)} B^{-1} \mathrm{~d} l$ 
The specific magnetic flux tube volume $W$ integrated from a unit area at ionospheric base $(l=0)$ to the MFM, was approximated in GVZ92 as $W \sim K r_{0} / B_{Z}$, where $K=4.5 \times 10^{15} \mathrm{~m}^{3} / \mathrm{Wb}$. To generate a FAC, an "azimuthal" pressure gradient $\nabla P_{\perp A}$ really enters Eq. (2). In other words, in the GVZ92 model the azimuthal pressure gradient was supposed to be proportional to the radial one due to smallness of the angle $\alpha$ between the vectors $\vec{\nabla} P$ and $\vec{\nabla} W$. In GVZ92 the angle $\alpha$ is a constant free parameter that determines only amplitude of the FAC density, not the form of its latitudinal profile, and hence the intensity of resulting auroral effects. It was assumed to be 0.01 to get a typical value of the resulting FAC for an arc/inverted-V. For a semiquantitative comparison with the measurements, attempted below, its value will be chosen to fit the average FAC density, $\sim 1 \mu \mathrm{A} \mathrm{m}^{-2}$, measured within the equatorial arc/inverted/V structure crossed by the $\mathrm{A} 3$ in the premidnight sector on the pass $840 \mathrm{~S}$.

When the magnetic field $B_{Z}\left(r_{0}\right)$ profile in the neutral sheet can be considered as given from a semi-empirical model, or measurements, the approximate radial profile of the plasma pressure $\boldsymbol{P}$ (supposed to be isotropic, as in GVZ92) can be deduced directly from the simplest form of the magnetostatic equilibrium in the $Z$ direction:

$P=\frac{1}{2 \mu_{0}}\left(B_{T}^{2}-B_{Z}^{2}\right)$

where $B_{T}$ is the tail lobe magnetic field.

This relation is valid in the MHD tail approximation when magnetic tension $(\vec{B} \cdot \vec{\nabla}) \vec{B}$ is negligible. Indeed, solutions of the Grad-Shafranov equation for stationary magnetospheric configurations with a MFM lead to quite different radial pressure profiles (see, for example, Hau et al., 1989). However, there are several aspects of the magnetospheric neutral sheet structure in the "wall region" that are not taken into account in the static Grad-Shafranov equation. First of all, the ion inertia is absent but is important in the "wall region". This is because the convection plasma flow is sharply decelerated (and deflected westward) in the narrow $B_{Z}$ minimum region, and the inertia of ions tends to partly compensate the magnetic tension, especially for the high- $\beta$ plasma in the neutral sheet. As a result, a pressure maximum most probably develops here due to decrease of the convection velocity and respective increase of density. Probably a local increase of pressure can occur here also due to some associated ion heating, as some calculations and observations in the "wall region" suggest. However, the magnetic pile up may not occur here fully because of violation of the frozen-in condition for ions. This means, secondly, that the MHD approach of the static Grad-Shafranov equation, strictly speaking, is not applicable for the "wall region" where the frozen-in condition for ions is violated and a crosstail "quasi-Pedersen" current is generated in westward direction. Thirdly, the dominance of the parallel pressure in the distant tail disappears in the stochastically isotropized "wall region", and the role of the magnetic tension is further decreased due to smallness of the magnetic field in the MFM region. So the assumption made in GVZ92 about a pressure maximum in the MFM region does not seem unrealistic, while is not necessary: the main conclusions of the model described will follow even in the case where $\vec{\nabla} P_{\perp A}$ is a constant vector. If the near coincidence of the pressure maximum with the MFM assumed in GVZ92 does not occur, this will lead to corresponding variations in the $j_{\|}$profile according to Eq. (2). In our view, these considerations allow us to test the model GVZ92 for comparisons with experimental data, taking into account that the real profile of the $j_{\|}$may be more complicated than assumed in this simplified scheme.

The sign of $\vec{\nabla} W$ changes near $R_{\min }$, the location of the minimal value of the $B_{Z}$. So the sign of the generated $j_{\|}$current must also change near $R z_{\min }$ forming a double sheet current. With Eq. (3) the sign of $\vec{\nabla} P$ also changes at this location, but even if we suppose that $\vec{\nabla} P_{\perp A}$ is a constant vector, the double sheet current pattern will still result from Eq. (2). So an intensive upward FAC which feeds an arc/inverted-V must appear near the ionospheric footprint of the neutral sheet region where the $B_{Z}$ value sharply increases, while its sign is determined by the direction of the $\vec{\nabla} P$ in respect to $\vec{\nabla} W$. Thus the steady auroral arc must originate from the "minimum- $B$ ", and form a double sheet FAC structure. These are the main predictions of the GVZ92 model, and for comparison with this experiment we proceed with calculations on its base.

\subsection{Comparisons with experiment during SMC period}

To compare the GVZ92 model with observations for this particular case, instead of assuming a hypothetical $\boldsymbol{J}_{\perp}$ radial profile for a narrow minimum of $B_{Z}$, we shall use the semi-empirical radial $B_{Z}$ profile in the neutral sheet derived for this SMC period by Sergeev et al. (1991, 1996) (hereafter SPP96). Comparisons will be made with the shape and relative intensity of the FACs measured from the A3 at ionospheric level at, and near, the equatorward-most arc, and those predicted by the GVZ92 model. The profile SPP96 was deduced from the sequence of high-energy particle isotropy boundaries (IB) as measured by the detectors on the NOAA- 6 and NOAA-7 satellites. In Fig. 7 the SPP96 semi-empirical profile and the hypothetical $B_{Z}$ profile from GVZ92 are plotted as solid and dotted lines, respectively. It can be noticed that the radial profiles GVZ92 and SPP96, qualitatively, have the same shape, but the spatial scale of the GVZ92 profile is smaller, while the respective radial gradients are correspondingly higher. Just to illustrate the similarity in shapes of the two curves, the GVZ92 profile was shifted outwards for $1.55 R_{E}$ and extended in radial direction by a factor of 4 around the minimum to make the distance between maximum and minimum, and the location of the minimum, the same as for SPP96. The modified curve GVZ92 $\mathrm{m}$ is shown in Fig. 7 as a dashed line GVZ92m and its similarity to SPP96 is evident. Though there is no specific physical significance in these modifications of the model profile, 
except to fit the observations better, this shows that radial gradients in the GVZ92 profile are qualitatively similar to the SPP96 profile, and that a much narrower magnetic field minimum (or several minima) are feasible in the frame of the GVZ92 model.

To map the resulting FAC densities to the auroral ionosphere we use the empirical mapping relations from the radial distances to auroral invariant latitudes, deduced in SPP96 from the IB algorithm and shifted by 0.5 degrees equatorward for the southern oval according to Sergeev et al. (1994).

As in the GVZ92 paper, the following simplifying approximations are adopted:

$$
\left\{\begin{array}{c}
B_{D}(r)=B_{0} r^{-3} ; B_{T}(r)=B_{D}+4 .[1-\exp ((7-r) / 4)] ; \\
B_{0}=31200 n T \\
W(r)=4.5 \cdot 10^{15} r / B_{Z}(r) ; j_{\|}^{i}=j_{\|}^{m} B_{i} / B_{Z}(r) \\
\Delta \Phi=K_{\mathrm{LEL}}^{-1} \cdot j_{\|}^{i} ; K_{\mathrm{LEL}}=1 \cdot 10^{-9} \mathrm{Mho} / \mathrm{m}^{2}
\end{array}\right.
$$

Here $r$ is expressed in Earth's radii $R_{E}$, magnetic fields $B_{D}, B_{T}$, and $B_{Z}$ are in $\mathrm{nT}, W$ in $\mathrm{m}^{3} / \mathrm{Wb}$, FAC density at exit from the plasma sheet, $j_{\|}^{m}$, and at the ionospheric level, $j_{\|}^{i}$, are in $\mathrm{A} / \mathrm{m}^{2}$, and the FA potential drop, $\Delta \Phi_{\|}$, is in volts. It can be noted that these approximations are consistent with a small FA acceleration $\Delta \Phi_{\|}$in the observed equatorial arc/inverted-V of $\sim 0.6 \mathrm{kV}$.

Two semi-empirical profiles of the $B_{Z}$ in the neutral sheet were deduced in SPP96: one from the locations of particle isotropy boundaries measured from low-altitude satellites (IB-algorithm), and another from adaptive magnetic field modelling based on magnetic field data from several high-altitude satellites. These profiles are very similar which indicates their validity. Both these profiles and the fitted value $\alpha$, are used here in the GVZ92 model to deduce the FAC profiles at the ionospheric level to be compared with the measured profile on the A3 pass 840S (Fig. 8). To make the comparison clearer, we plot not only the modelled FAC density, but also its integral along the orbit which gives the modelled $D B_{y}$ (plus a constant). The main variation of the $D B_{y}$ component which implies a double sheet current loop with the upward current branch collocated with the arc/inverted-V (bottom panel) is well reproduced by the model. The total widths of the upward FAC observed and modelled agree quite well: they are both about 0.5 degrees ILAT (see Fig. 8). The most intense part which we identify with the arc is indeed much narrower, and we consider it as one of the most important results of the model: this shows a simple explanation of the narrow arc width $(\sim 10-20 \mathrm{~km})$ due to just magnetic moment conservation in the flux tubes of the magnetic field minimum.

The total width of the upward FAC region is defined in the model mainly by the width of large radial gradient in the $B_{Z}$ magnetic field minimum region. It needs to be noted that according to the IB-derived mapping, the upward FAC region in this case originated from the plasma sheet region from $\sim 12.2$ to $\sim 16.2 R_{E}$ which is a wide enough region for various small-scale variations to be present, but not described by the adopted smoothed

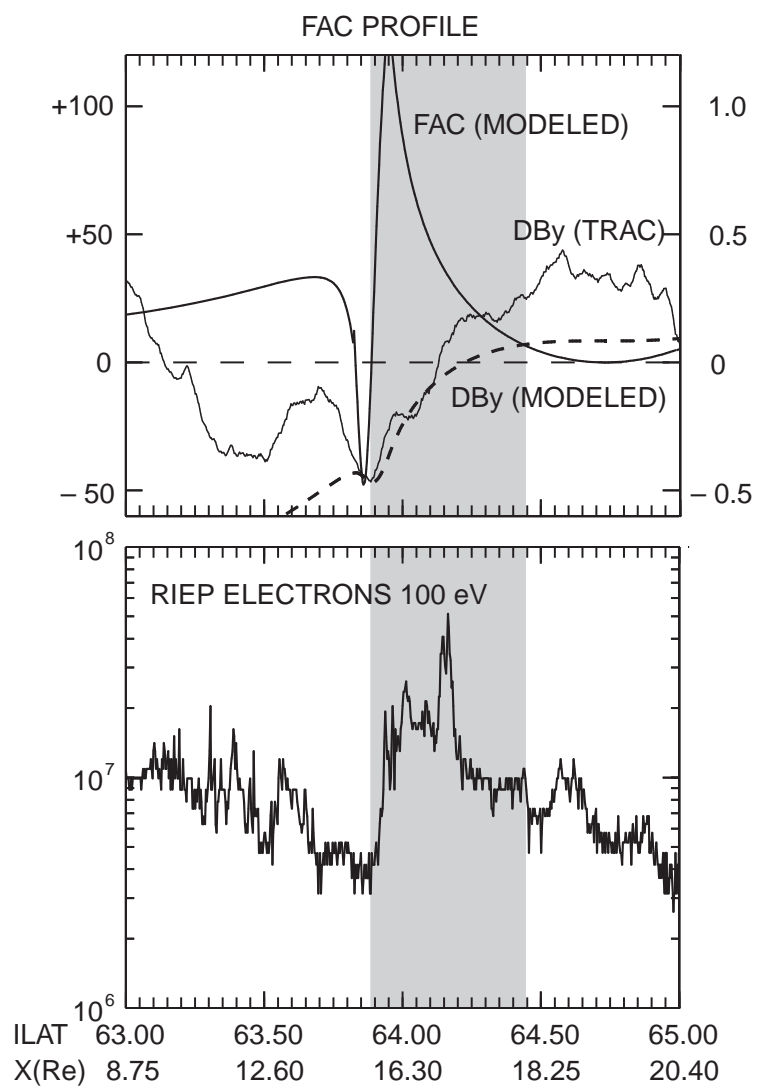

Fig. 8. Modelled field-aligned current (FAC) latitudinal profile (bold line) and equivalent $D B_{y}$ magnetic field perturbation (dashed line) at ionospheric altitudes, compared to measured $\Delta B_{y}$ variations (nT) of the horizontal magnetic field (running averages on $1.2 \mathrm{~s}$.). The electron flux latitudinal profile at $100 \mathrm{eV}$ (RIEP spectrometer) is given for comparison in the bottom panel and demonstrate that the upward FAC between ILAT $=63.9$ and 64.45 (shaded area) coincides with enhanced fluxes of low-energy $\leq 1 \mathrm{keV}$ electrons (the weak arc). $X\left(R_{E}\right)$ is the projected $X$ distance in the tail

magnetic minimum shape. Thus except for the intense upward current in the main arc, the detailed structure of the upward current region, and to some extent its intensity, is not a critical model parameter. It can be easily adapted within the frame of the model, by slightly changing either magnetic field minimum shape, or the pressure gradient shape (not measured directly), or both, if the self-consistency is neglected. We do not consider such adaptations as warranted at this stage of the model development. Thus we state that striations and other small-scale details are not reproduced by the model.

Consider now the comparison of the model with the downward current branch of the double sheet current associated with the arc. Its existence (the double sheet FAC pattern) is inherent in the magnetic minimum origin and the Eq. (2). So we consider it as an aspect of the model supported by observations. The narrow modelled region of the downward current (tens of kilometres wide) encompasses the magnetic minimum in the plasma sheet from $\sim 10.5$ to $12.2 R_{E}$. Again, this extended tail region can well have additional details not included in the model. The modelled width and shape depends on the mentioned uncertainties in the realistic 
detailed pressure and magnetic field profiles (possibly deviating from the smoothed shape of SPP96), and also on some other factors which we do not consider here. But the region of the observed downward current, according to the mapping given in SPP96, extends inward to the geostationary orbit, i.e. far outside the magnetic field minimum region modelled here. Thus no correspondence can be expected between the model and the full width of the downward current. So, a comparison of the full width of the observed and modelled downward current region cannot be considered as a test for the model.

An additional small-scale FAC feature (also in the form of a double sheet current loop) seen in the centre of the observed wide double sheet current loop, is not quite reliable due to low amplitude of the respective disturbance in the measured $D B_{y}$ component, but it can be real. In such a case it maps to some structure located at $\sim 9 R_{E}$ in the plasma sheet, possibly a secondary smallscale minimum or from another feature located well earthward from the main "minimum- $B$ " region, or from another feature.

We can conclude that generally the agreement of the model FAC profiles, resulting from a rather simple GVZ92 model, with the experimental data gathered during the SMC period, may be considered as reasonably good both in the shape (a double sheet current loop) and location in latitude, while the modelled FAC amplitude remains arbitrary.

\section{Discussion of results}

\subsection{Arc/inverted-V at the equatorial edge of auroral oval}

Firstly, we compare the position of the equatorward arc/ inverted-V structure observed by A3 around ILAT $=63.5$, MLT $=22.0$, with the locations of the particle boundaries determined, or compiled by Y94 (their Fig. 11). According to Y94 the isotropic boundary (IB) for $30 \mathrm{keV}$ ions at MLT $\sim 22 \mathrm{~h}$ was located at ILAT $\sim 64.0$; so the arc/inverted-V location observed by A3 well coincides with this IB, as was supposed in the theory by GVZ92 based on the mapping concepts developed earlier (Feldstein and Galperin, 1985; Galperin and Feldstein, 1991). The time duration and stability of this arc/inverted-V system cannot be determined from a single spacecraft crossing. But the auroral imagery data from the DE-1 satellite presented in Y94, very similar latitude profiles recorded from the A3 satellite both in the premidnight and evening sectors of the oval, about 45 minutes apart, and nearly simultaneous similar data from the DE-2 satellite, all give confidence for a long time $(\geq 1 \mathrm{~h})$ stability and large longitudinal extent of the arc/inverted- $\mathrm{V}$ system at the equatorial boundary of the oval.

However, the existence of the weak equatorial arc, its time stability and location at the equatorial edge of the oval of discrete forms, and its respective mapping to the near-Earth edge of the CTC, are all facts in contrast to the views previously described in Y94 and SPP96. In the latter papers all this region is considered as the diffuse precipitation region with only transient auroral features. Possibly, it was difficult to show by the all-sky cameras used in Y94 the discrete arc/inverted-V structure at the equatorial edge of the oval/polar edge of the diffuse auroral zone. We admit that its location at the polar edge of the bright diffuse auroral glow and its low contrast in the total energy flux (only lowest energies were enhanced) makes its identification really difficult in visible light outside the near-zenith observations. As a result, the oval of discrete forms is characterized in Y94 and SPP96 only by the bright polar band, while the region between it and the diffuse zone was considered as a "depleted luminosity region", with only transient auroral features poleward from the diffuse auroral zone. Consequently it was concluded there (SPP96, p. 573) that these observations "...imply that the discrete auroral arcs map to the distant tail $\left(R>30 R_{E}\right)$ and to the plasma sheet boundary layer as observed at $R=20 R_{E} \ldots$... Evidently this conclusion contradicts the data described already, as well as the oval mapping concepts developed by Feldstein and Galperin (1985), Galperin and Feldstein (1991, 1996), and others. These concepts, at least for the near-Earth plasma sheet, now are directly confirmed by various data (see, for example, Hones et al., 1996), and seem well established.

Bosqued et al. (1993) described latitude distributions of electron and ion intensities in a steady nightside oval from the A3 satellite data which are similar to those described in the SMC period. They noted a "gap" in the low energy ion intensity usually appearing between the polar band of electron precipitation, and an arc/inverted-V equatorward from the gap. From their statistical results it is seen that an arc is "routinely present" equatorward from the gap. Obviously, the "gap" depends on the instrument sensitivity threshold and must not be taken too formally. These results have many similarities with the pass $840 \mathrm{~S}$ described here, and again indicate that the inferred tail structure during this pass was rather typical for steady conditions. The auroral gap in that paper, as a whole, is ascribed to the projection of the near-Earth tail region were nonadiabatic ion scattering is taking place due to a decrease in the $B_{Z}$ profile, and resulting Kappa parameter $\sim 1$ (Büchner and Zelenyi, 1989). In the equatorial plane the earthward boundary of this region is referred as the "wall region" by Ashour-Abdalla et al. (1993), and Bosqued et al. (1994). Arguments were presented already for a more precise mapping of this region to the equatorial arc/inverted- $\mathrm{V}$ and the region around it, which was supposed in GVZ92 to be the projection of the MFM at the earthward edge of the neutral sheet. Also, Pulkkinen et al. (1995) concluded that the "gap" during a typical double oval case is mapped to $20-30 R_{E}$ downtail (which is far beyond the MFM), while the polar auroral band mapped to beyond $30-40 R_{E}$. These independent results are consistent with the above mapping of the MFM.

To summarize, during the SMC period studied here, a large latitudinal width for the double oval of discrete auroral forms is thus implied. This double oval maps to 
the whole extended plasma sheet from its inner edge or, more precisely, from the negative gradient (in the GSM $X$ direction) of the large-scale CTC (at about 12.5-15 $R_{E}$ in this case), as far as its distant part located probably around $100 \pm 50 R_{E}$ (see Sect. 5.4) These characteristics of the oval and its mapping are all in full agreement with the mapping concepts advocated by Feldstein and Galperin (1985), and Galperin and Feldstein (1991).

\subsection{Comparisons with the GVZ92 model}

Here we discuss how the radial plasma density profile and the resulting minimum- $B$ profile in the plasma sheet affect the modelled FAC profile, and thus the arc's intensity. In GVZ92 this profile (reproduced in Fig. 7), was chosen to obtain a narrow double FAC sheet generator for a typical narrow auroral arc/inverted-V supposing the $B_{Z M I N} \sim 5 \mathrm{nT}$. However, the SPP96 profile derived by Sergeev et al. (1991, 1994) for the SMC period considered here, leads to a wider radial/ latitudinal extent (approximately 4 times) of the MFM considered to be the FAC generating structure in the plasma sheet, but with about 3 times lower $B_{Z M I N}$. Correspondingly, the respective magnetic field and pressure gradients are comparable, as well as the resulting FACs and auroral effects.

During the development and further discussions of the GVZ92 model during recent years, a question was risen concerning the stability of the additional line current (ALC) sheet in the $X Y$ plane which was not considered in the simple $1 \mathrm{D}$ form of the model. Evidently, for the isotropic pressure case, a more rigorous treatment is possible, in comparison with that in GVZ92, of the magnetic field structure in equilibrium with plasma pressure with the use of magnetic vectorpotential $\mathbf{A}\left(r_{0}, \mathrm{z}\right)$ and Grad-Shafranov equation. Its solution, with the given $B_{Z}\left(r_{0}\right)$ as a boundary condition, can be sought in a way described in Hau et al. (1989), and Hau (1991). For an adiabatic lossless convection, Hau et al. (1989) show that to avoid the "pressure balance inconsistency", a minimum must appear in the magnetic field $B_{Z}\left(r_{0}\right)$ profile. We must note that the steady-state $B_{Z}\left(r_{0}\right)$ profiles deduced in GVZ92 and in SPP96 are very similar to those deduced in Hau et al. (1989), and Hau (1991), as was noted in the two former papers. However, it was stated in Sect. 4.1. that the static Grad-Shafranov equation does not take into account some specific features of the MFM region, such as ion inertia of the decelerated and deflected ion flow there, and a violation of the frozen-in condition for ions. As shown by Ashour-Abdalla et al. (1994) and Bosqued et al. (1994), the pressure anisotropy, and even the nondiagonal components of the stress tensor, are important in the "wall region" for a pressure balance. The total configuration of magnetic fields, currents and particle distributions obtained in their modelling appeared to be rather close to equilibrium and in many aspects resembled observations. In particular, it was concluded that in the "wall region" the ions are strongly heated and isotropized, and that in the equatorial plane the pressure increases significantly towards the duskside. This means that ions obtain just an azimuthal pressure gradient that is needed for a FAC generation in this region. These results were recently confirmed by measurements (Frank et al., 1995), and amplified by more advanced calculations using magnetic and electric fields self-consistent within a dynamic MHD model (Peroomian et al., 1997). In view of these results it seems that the simplest plasma pressure and magnetic field distributions adopted in GVZ92 are qualitatively reasonable, though evidently a rough approximation.

One specific, though indirect additional piece of evidence for the "wall region" origin of the arc is the shape of the electron spectrum not typical for an inverted-V structure (see Fig. 4), i.e. a power-law, or Kappa-distribution shape, with a decrease both at low and high energies, and no evidence for a potential drop $\geq 1.0 \mathrm{kV}$. We note that this spectral distribution is very similar to the plasma sheet electron spectra observed from ISEE-1 at $\sim 30 R_{E}$ by Christon et al. (1991) during disturbed periods and, thus, is consistent with a "wall region" origin, without significant acceleration. The reason for this is that, in contrast to non-adiabatic ions, electrons remained adiabatic in the "wall region". Thus entering the MFM region they had to restore their original distribution in the distant tail where the $B_{Z}$ value was comparable to that in the "wall region", i.e. was $\sim 1.5-2 \mathrm{nT}$. These values are not inconsistent with the magnetic data in the tail collected in SPP96 (see their Fig. 7c, left side, and Fig. 8a).

An independent consistency test of the $B_{Z}$ tail profile and the mapping relation can be furnished by the location of the ion intensifications near the equatorial arc (see Sect. 3), around $\sim 0835: 40$ UT for $1.8 \mathrm{keV}$ ions and around $\sim 0835: 20$ UT for $0.1 \mathrm{keV}$ ions. Such a maxima could be tentatively interpreted as resulting from non-adiabatic loss cone scattering of the earthward drifting ions (Delcourt et al., 1996) at the tailward side of the MFM. Thus it can be supposed that some ion precipitation intensity maxima will appear at the ionospheric locations mapped from their respective resonance scattering regions in the equatorial plane if convection will not displace them in latitude. By using the semi-empirical SPP96 $B_{Z}$ profile for this SMC interval we determined the locations in the neutral sheet where the non-adiabatic resonance condition $(K \sim 1)$ is fulfilled for the $1.8 \mathrm{keV}$ and $0.1 \mathrm{keV}$ ions. These locations appear to be at $16.8 \pm 0.35 R_{E}$ and $12.4 \pm 0.3 R_{E}$ respectively. As convection in this region was mainly zonal (see Figs. 4 and 5 in Y94), the respective latitudinal time-of-flight shift of precipitating ions is probably small and can be neglected in mapping these plasma sheet regions to ionospheric altitudes by using the semi-empirical mapping relation already defined in Sect. 4.2. While its precision is rather low (due to a small slope of the mapping curve in the MFM), the expected precipitating regions are at ILAT = $64.8 \pm 0.2$ for $1.8 \mathrm{keV}$, and at ILAT $=64.1 \pm 0.1$ for $0.1 \mathrm{keV}$ (Fig. 3c, wide black arrows below the respective flux profiles), which is close to observed ion maxima, and have similar separation in latitude but 
slightly displaced poleward (about $50 \mathrm{~km}$ ). At the same time, the equatorial auroral arc happened to be close to these two ion intensity maxima, i.e. in the region of the MFM where the main part of the ion distribution function is stochastic as was supposed in GVZ92 and in Galperin (1992).

Finally we may comment about the model developed by Samson et al. (1992) and Liu et al. (1995), which considers the slow time evolution of a homogeneous arc. We suppose that the MFM could be a stable location of a slowly oscillating arc. The implied decrease of the Alfven velocity in the MFM flux tube (due to decrease of equatorial magnetic field and increase of plasma density) and thus an increase of the resonance period, could be qualitatively consistent with that oscillation theory. The MFM then could be a site of resonance oscillations with a lifetime much longer than the oscillation period and determined by the lifetime and stability of the MFM. So we consider this model to be complementary to ours, but only further development of both could show their consistency.

A last comment concerns the splitting of the equatorial arc/inverted- $\mathrm{V}$ to narrow filaments $(\leq 1.5 \mathrm{~km})$ in the $100 \mathrm{eV}$ intensity (Figs. 4 and 8); it cannot be reproduced by the GVZ92 model. Such narrow arc filaments are often observed within a homogeneous auroral arc (Nadubovich and Starkov, 1962; Nadubovich, 1969; Oguti, 1981; Trondsen and Cogger, 1997), but they usually involve higher auroral electron energies. An approach to describe them is undertaken in the models by Tverskoy (1982 a, b) and by Samson et al. (1992), though their comparisons with rare high resolution measurements such as shown in Fig. 4, or more comprehensive, such as from the FAST satellite, are still to be completed.

\subsection{Why were there no substorms during the SMC period?}

In summary, data obtained during the November 24, 1981 SMC period on convection both at the dayside (Despirak et al., 1994; SPP96; Galperin et al., 1998), and on the nightside (Y94; Sergeev et al., 1990, 1991, 1994, SPP96), consistently with the results of this study, indicate (1) stationary conditions throughout the magnetosphere with a strong convection, (2) quasi-steady intensive electrojets, and (3) a generally stable auroral double oval pattern. They show a relatively stable polar cap area and a cross-polar cap potential difference of $80-90 \mathrm{kV}$. In other words, the magnetic flux is steadily, or quasi-steadily eroded at the dayside magnetopause, and quasi-steadily returns from the nightside tail, without large-scale explosive reconnection bursts in the near tail.

Naturally, an obvious question arises in connection with a prolonged SMC period: what is the cause of the absence of substorm onsets during such a prolonged IMF- $B_{Z}<0$ condition prevailing during that period? This question is, at the same time, about at least one of the necessary conditions for a substorm onset, which apparently was not met during the SMC period. Was it a lack of some pre-condition for a specific local plasma instability (Lui, 1991a, b; 1992), or a lack of a local exhaust of hot plasma in the plasma sheet caused by reconnection at the near-Earth neutral line and manifested in the equatorward motion of the prebreakup arc (Atkinson, 1982, 1986, 1996; Baker et al., 1993), or an inhibition of some kind of an interchange instability, or something else?

One of the main findings of this study seems to be the steady existence, during the SMC period, of a weak arclike feature observed at the equatorial edge of the oval compared to rather intensive arc/inverted-Vs typically observed in this region. Could this difference in brightness (i.e. precipitating energy flux), or in the FAC density, or in the implied conductivity gradient in ionosphere, be important for the long-term stability of the arc/inverted$\mathrm{V}$ structure, and hence for all the near-Earth's tail? Evidently, the observed weak FACs and resulting low electron acceleration will not alter much the ionospheric conductivity profile across the arc in comparison with that in the diffuse auroral band. Thus, among various mechanisms of the substorm onset (see reviews by Lui, 1991a, b, and Erickson, 1993), those which are based on the conductivity variations in the underlying ionosphere, such as proposed by Kan et al. (1988), Rothwell et al. (1988, 1991), or by Erickson et al. (1991), can be inoperative in these conditions. The near absence, or at least a low value, of a flow shear at the arc as revealed from the electric field data obtained by A3 (see earlier) does not provide conditions necessary for the Harang Discontinuity mechanism proposed by Lyons and Samson (1992), at least near the location of the A3 arc crossing. At the plasma sheet altitudes, fast large-scale convection during the SMC together with weak FACs in the arc apparently could slow down, or even impede, the exhaust of the hot plasma from the magnetospheric flux tubes of the arc/inverted-V considered by Atkinson $(1986,1996)$ as a possible cause of substorm onset. As was shown by Hau et al. (1989) and others (see earlier), the existence of the minimum in the $B_{Z}$ radial profile allows for stationary solutions avoiding the "pressure balance inconsistency" (Erickson and Wolf, 1980).

These qualitative considerations are insufficient to conclude that a substorm onset was indeed impeded by these factors, but they favor at least a longer recovery phase, or a longer delay to the next substorm. However the direct cause of a substorm onset, as well as its absence during the SMC periods, remains an unsolved problem.

A natural way for a substorm onset development was suggested by GVZ92, as was mentioned above: a decrease of the minimum- $B$ field in the equatorial plane to low enough $B_{Z \text { MIN }}$ values, say, $\leq 1 \mathrm{nT}$. The smooth minimum in the semi-empirical $B_{Z}$ radial profile, $B_{Z \mathrm{MIN}}$ $\sim 1.5-2 \mathrm{nT}$, apparently was nearly steady during the SMC period on November 24, 1981 according to Fig. 7c in SPP96, and no substorms occurred. Such $B_{Z M I N}$ values would not allow for the non-adiabatic scattering for the core of the plasma sheet electron distribution function for which a lower magnetic field is needed. So the stability of the CTC during the SMC was maintained 
at least in respect to the tearing processes, while conditions for the electron demagnetization were not reached. It can be also noted that in several other case studies Pulkkinen et al. (1992) have found a good correspondence between substorm onsets, or a local auroral activation cases, and the time/space region in the plasma sheet where the electron motion chaots was expected due to a decrease of the magnetic field as deduced from the adaptive magnetospheric modelling. These comparisons seem to be qualitatively consistent with the plasma sheet stability conditions during the SMC period. Evidently further study of this interesting problem is needed.

We conclude that the data described concerning on the magnetospheric conditions during the long SMC period without substorms are consistent with some views about necessary conditions for a substorm onset. In particular, these data are consistent with the dominant role of a local deepening of the MFM as the immediate cause of the substorm onset, or of a local auroral activation, as was suggested by GVZ92. Indeed, in the latter scenario the deep minimum in the magnetic field can arise quite naturally during a growth phase when cross-tail current is growing, and at the right place and time for an onset. Further development of the GVZ92 model for the substorm onset, or local auroral activation, is considered in Galperin and Bosqued (1998) and Galperin (1998).

\subsection{Polar auroral band and its mapping to the distant tail}

Throughout the long SMC period there existed a bright and relatively steady auroral band at the polar edge of the auroral oval (see, Y94, SPP96). Thus it is tempting to identify this observed polar band of the double oval with the result of the field-aligned currents originated at the distant turbulent reconnection region.

It was conjectured long ago (Russell, 1972; Coroniti and Kennel, 1972; and for a recent discussion, Lockwood and Cowley, 1992; Kennel, 1995) that as the average reconnection rate at the dayside is generally not matched by the reconnection rate in the far tail, substorms, or localized magnetic field dipolarisations (and BBF-type bursts in the tail) are needed to restore the average magnetostatic equilibrium throughout the magnetospheric system. It is clear that, for an SMC interval, such an equilibrium is maintained quasisteadily, so that substorms are "not needed" to impulsively return the magnetic flux from the tail to the near-Earth's magnetosphere. This requires a relatively steady location of the distant reconnection region, as well as the adequate steady reconnection rate and plasma supply in the far tail. Usually it is assumed that the quasi-steady reconnection occurs at a distant neutral line (DNL). Another possibility (Galperin, 1995; Galperin and Feldstein, 1996) is a vast turbulent plasma sheet region in the far tail where quasi-steady turbulent magnetic field reconnection is maintained.

During a substorm, Elphinstone et al. (1995b) demonstrated that the space/time development of the polar auroral band, which usually appears during the recovery phase, is separated from the equatorial auroral band related to the near-Earth central plasma sheet and may be directly related to the DNL. The polar auroral band of the double oval can be collocated with the VDIS-2 ion precipitation structures at the polar edge of the oval. Elphinstone et al. (1995b) concluded that at least occasionally, the polar auroral band is to be mapped to the PSBL where the VDIS-2 structures are observed. We note that this association is by no means typical. In all the VDIS-2 cases found from the A3 satellite (99 events), a VDIS-2 structure was distinct from the polewardmost inverted- $\mathrm{V}$, and located poleward from it by about 1 degree of latitude in average (Bosqued et al., 1993a). Consequently, the polar auroral band usually maps to the distant plasma sheet, and not to the PSBL. However we may note that the quasistationary, extended, and durable polar auroral band observed during the SMC (on the DE-1 images presented in Y94) is quite distinct from the dynamic, and relatively short-term $(\sim 0.5-1 \mathrm{~h})$ polar auroral band of the double oval during a recovery phase in a typical substorm.

Large-scale kinetics (LSK) modelling can shed new light on the association between the distant tail and associated auroral features. It has been demonstrated (see for a review, Ashour-Abdalla et al., 1993) that ions injected from the plasma mantle and crossing the distant neutral sheet will undergo a strong non-adiabatic scattering. 2D (Bosqued et al., 1993), as well as 3D simulations (Bosqued et al., 1994), have shown that a part of accelerated ions will follow Speiser-type orbits and precipitate as a band of superimposed VDIS-type 2 structures at the poleward edge of the auroral oval (Bosqued et al., 1994). For steady conditions (not necessarily very quiet) the same simulations showed that a strong cross-tail current (CTC) develops near the DNL around $100 R_{E}$ downtail which leads to an intense upward FAC (and a bright polar auroral band) around ILAT $\sim 72-76^{\circ}$ at ionospheric altitudes extending from MLT $\sim 21 \mathrm{~h}$ to $\sim 03 \mathrm{~h}$. The VDIS oval is immersed in this poleward region of intense FACs, i.e. presumably at, or poleward from, the polar auroral band, which is detached poleward from the equatorial band of discrete forms at lower latitudes (Bosqued et al., 1994). This polar auroral band together with the equatorward-most arc, or band, of the oval described above will form the double oval appearance. These results were confirmed by model calculations by Onsager and Mukai (1995) that were able to reproduce the observed ion precipitation characteristics across the auroral oval, including a VDIS structure at its polar edge and a mid-oval "gap" mapped to the rather distant plasma sheet region, at $45-55 R_{E}$, much tailward from the "wall region". All these findings are consistent with the GVZ92 model and mapping of the equatorial auroral arc of the oval to the "wall region".

A last comment is related with the A3 observation of an auroral polar band striated to multiple narrow auroral arcs. This arc's splitting is in qualitative accord with the layering of the FAC sheets in the double oval 
polar band as observed by Echim et al. (1997) from the MAGION-2 and MAGION-3 satellites during double oval conditions. Such a FAC layering reminds us of the concepts by Atkinson et al. (1989) about multiple X-line origins of such arcs, but favors a radially extended reconnection region, not a single DNL.

Thus, to summarize, these observations allow us to reformulate the question on the absence of substorms during the SMC period in relation to the polar auroral band. So the question is: why, at least during this particular SMC period, this band which is presumably related to the distant reconnection region, or DNL, was stable and persisted for a very long time? In other words, what plasma parameters in this case determined the steady reconnection rate in the far tail (probably reflected to some extent by the polar auroral band)? Or, what specific features determined the regular supply of magnetic flux and plasma to the magnetosphere from the nightside, which matched the average dayside reconnection rate (magnetic flux erosion)? The answers to these questions apparently may be obtained only when the phenomena at the far magnetospheric tail, at the dayside magnetopause, and in the auroral oval, are considered as inherent, interdependent processes within a unified, and nearly equilibrated, plasma system.

\section{Conclusions}

1. A steady weak auroral arc, located at the polar edge of the diffuse auroral band, i.e. at the equatorial boundary of the stationary oval, was observed by the A3 and DE-2 satellites during the November 24, 1981 SMC period.

2. This arc is shown to be formed inside a relatively narrow, but extended in local time, magnetic field minimum, MFM (down to 1-2 nT) located in the transition region from the dipole-like to stretched magnetic field in the nightside near-Earth's plasma sheet. This unique observation confirms the main hypothesis of the GVZ92 "minimum- $B$ " model concerning the "arc root" location.

3. Only a very small angle $\alpha \sim 0.01$ between the vectors $\vec{\nabla} W$ and $\vec{\nabla} P$ is needed to match the observed FAC density in the arc and supports the hypothesis adopted in the GVZ92 model that the azimuthal pressure gradient $\vec{\nabla}_{Y} P$ is proportional to the radial pressure gradient $\vec{\nabla}_{X} P$.

4. The observed narrow double sheet FAC structure associated with the arc with a total width $\leq 0.5^{\circ}$ ILAT, is correctly predicted, due to the changing sign of the $\vec{\nabla} W$ at the MFM. The narrowness of the observed arc's main intensity maximum, the location and width of the upward current region, are all reasonably well reproduced by the modelled FAC. However multiple striations of the arc precipitation are not reproduced by the adopted simple form of the MFM. Obviously, by introducing arbitrarily additional small details in the $\vec{\nabla} W$ and $\vec{\nabla}_{Y} P$ profiles it seems possible to formally reproduce these observations within the frame of the model.
5. The observed wider downward current region which extends down to ILAT $\leq 63.0$ degrees (the region II current) is mapped inward from the MFM. According to the SPP92 mapping, this current was generated in the wide region from about the geostationary orbit till $\sim 10 R_{E}$.

6. These observations and modelling support the assumptions made in GVZ92 that the prebreakup arc also originates from the narrow elongated MFM, and thus that substorm onset starts within the MFM.

7. The steady appearance over a long period of time of a band of intense precipitation and resulting bright auroral band at the polar oval border during this SMC period allows us to suppose its origin from, and mapping to, the radially extended quasi-steady distant turbulent reconnection region in the far tail, or the DNL.

8. These comparisons were made for only one particular SMC period. So it seems necessary to check the applicability of these conclusions for other SMC periods, and for other cases of steady, or quasi-steady auroral arcs in the oval, and especially for the prebreakup arcs in view of their importance for the substorm onset problem.

Acknowledgements. This work was supported by the INTAS grant 94-1695, and by the RFBR grant 97-02-16333. Discussions of Y.I.G. with Y. I. Feldstein, O. A. Troshichev and V. A. Sergeev, and of J.M.B. with M. Ashour-Abdalla, V. Peroomian and M. El Alaoui are gratefully acknowledged. The authors thank N. V. Jorjio, C. Guérin and D. Lagoutte for the help in data treatment and presentation, and J.-J. Berthelier and C. Béghin, PIs of the A3 experiments, for generously sharing their results on the A3 satellite, and to D. V. Chugunin and V. A. Stepanov for help in calculations. We thank dr. A.Yahnin for indicating to us the existence of the NOAA 6 data in the evening sector. DE-2 electric and magnetic field data (PIs: N. Maynard and M. Sugiura) were kindly provided to us by J. King through the NSSDC CD-ROM.

Topical Editor K.-H. Glassmeier thanks P. Escoubet and another referee for their help in evaluating this paper.

\section{References}

Akasofu, S.-I., The development of auroral substorm, Planet. Space Sci., 12, 273-282, 1964.

Ashour-Abdalla, M., L. M. Zelenyi, J. M. Bosqued, V. Peroomian, D. Schriver, and R. Richard, The formation of the Wall Region: consequences in the near Earth magnetotail, Geophys. Res. Lett., 19, 1739-1742, 1992a.

Ashour-Abdalla, M., L. M. Zelenyi, J. M. Bosqued, V. Peroomian, Z. Wang, D. Schriver, and R. Richard, Effects of near-Earth stochastic acceleration and reflections of magnetotail ions on the formation of auroral arcs, in, Ed. Mattok, C., SUBSTORMS 1 ESA SP-335, Noordwijk, pp 545-552, $1992 b$.

Ashour-Abdalla, M., J. Berchem, J. Buchner, and L. M. Zelenyi, Shaping of the magnetotail from the mantle: global and local structuring, J. Geophys. Res., 98, 5651-5676, 1993.

Ashour-Abdalla, M., L. M. Zelenyi, V. Peroomian, and R. Richard, Consequences of magnetotail ion dynamics, J. Geophys. Res., 99, 14 891-14 916, 1994.

Atkinson, G., The narrow-channel approximation for magnetospheric flows, J. Geophys. Res., 87, 7489-7503, 1982.

Atkinson, G., Verification of quantitative relationship among Birkeland current sheet motion, intensity, and convective velocity and also of criterion for expansion onset, J. Geophys. Res., 91, 8929-8935, 1986. 
Atkinson, G., Narrow-channel convection with free boundaries and energetic particle drifts: 1 . Basic properties of the convection, Preprint, 1-25, 1996.

Atkinson, G., F. Creutzberg, R. L. Gattinger, and J. S. Murphree, Interpretation of complicated discrete arc structure and behavior in terms of multiple X-lines, J. Geophys. Res., 94, 5292-5302, 1989.

Baker, D. N., T. I. Pulkkinen, R. L. McPherron, J. D. Craven, L. A. Frank, R. D. Elphinstone, J. S. Murphree, J. F. Fennell, R. E. Lopez, and T. Nagai, CDAW 9 analysis of magnetospheric events on May 3, 1986: event C, J. Geophys. Res., 98, 38153834, 1993.

Béghin, C., J. F. Karczewski, B. Poirier, R. Debrie, and N. Massevitch, The ARCAD-3 ISOPROBE experiment for high time resolution thermal plasma measurements, Ann. Geophysicae., 38, N5, 615-629, 1982.

Berthelier, J. J., A. Berthelier, Y. I. Galperin, V. A. Gladyshev, G. Gogly, M. Godefroy, C. Guérin, and J. F. Karczewski, DC magnetic field observations on board the A3 satellite: the TRAC experiment, Ann. Geophysicae., 38, 635-642, 1982.

Borovsky, J. E., Auroral arc thickness as predicted by various theories, J. Geophys. Res., 98, 6101-6138, 1993.

Bosqued, J. M., AUREOL-3 results on ion precipitation, Phys. Scripta, T18, 158-166, 1987.

Bosqued, J. M., M. Ashour-Abdalla, M. El Alaoui, V. Peroomian, L. M. Zelenyi, and C. P. Escoubet, Dispersed ion structures at the poleward edge of the auroral oval: low-altitude observations and numerical modelling, J. Geophys. Res., 98, 19 181-19 204, 1993a.

Bosqued, J. M., M. Ashour-Abdalla, M. El Alaoui, L. M. Zelenyi, and A. Berthelier, AUREOL-3 observations of new boundaries in the auroral precipitation, Geophys. Res. Lett., 20, 1203-1206, 1993b.

Bosqued, J. M., M. Ashour-Abdalla, V. Peroomian, R. L. Richard, and L. M. Zelenyi, Auroral precipitation patterns: observations and 3D simulations, in Substorms 2, Proceedings of the Second Int. Conf. on Substorms, University of Alaska, Fairbanks, pp. 365-372, 1994.

Bosqued, J. M., H. Barthe, J. Coutelier, J. Crasnier, J. Cuvilo, J. L. Médale, H. Rème, J. A. Sauvaud, and R.A. Kovrazhkin, The low energy electron and ion spectrometers on the AUREOL-3 satellite: the SPECTRO experiment, Ann. Geophysicae., 38, N5, 567-582, 1982.

Boström, R., Mechanisms for driving Birkeland currents, in Physics of the Hot Plasma in the Magnetosphere, Eds. Hultqvist, B., and L. Stenflo, Plenum, N.Y., pp 341-365, 1975.

Buchner, J., and L. M. Zelenyi, Chaotization of electron motion as the cause of an internal magnetotail instability and substorm onset, J. Geophys. Res., 92, 13 456-13 466, 1987.

Buchner, J., and L. M. Zelenyi, Regular and chaotic charged particle motion in magnetotail like field reversals, 1. Basic theory of trapped motion, J. Geophys. Res., 94, 11 821-11 842, 1989.

Christon, S. P., D. J. Williams, D. G. Mitchell, C. Y. Huang, and L. A. Frank, Spectral characteristics of plasma sheet ion and electron populations during disturbed geomagnetic conditions, J. Geophys. Res., 96, 1-22, 1991.

Coroniti, F. V., and C. F. Kennel, Changes of magnetospheric configuration during substorm growth phase, J. Geophys. Res., 77, 3361-3370, 1972.

Delcourt, D. C., G. Belmont, J.-A. Sauvaud, T. E. Moore, and R.F. Martin Jr., Centrifugally driven phase bunching and related current sheet structure in the near-Earth magnetotail, $J$. Geophys. Res., 101, 19 839-19 847, 1996.

Despirak, I., A. Lubchich, A. G. Yahnin, Y. I. Galperin, S. Vennerstrom, O. Aulamo, and J. D. Craven, Region of cusplike precipitation in day side high latitudes during steady magnetospheric convection, Geomagn. Aeron. (in English), 34, N5, 5-10, 1994.

Echim, M., M. Ciobanu, O. Balan, A. Blagau, O. Marghitu, E. Georgescu, Y. I. Galperin, N. V. Jorjio, T. M. Muliarchik, A. L. Kotikov, E. M. Shishkina, and O. A. Troshichev, Multiple current sheets in double auroral oval observed from the MAGION-2 and MAGION-3 satellites, Ann. Geophysicae., 15, 412-423, 1997.

Elphinstone, R. D., J. S. Murphree, D. Hearn, L. L. Cogger, I. Sandahl, P. T. Newell, D. M. Klumpar, S. Ohtani, J. A. Sauvaud, T. A. Potemra, K. Mursula, A. Wright, and M. Shapshak, The double oval UV auroral distribution: 1. Implications for the mapping of auroral arcs, J. Geophys. Res., 100, 12 075-12 092, 1995a.

Elphinstone, R. D., D. Hearn, L. L. Cogger, J. S. Murphree, A. Wright, I. Sandahl, S. Ohtani, P. T. Newell, D. M. Klumpar, M. Shapshak, T. A. Potemra, K. Mursula, and J.A. Sauvaud, The double oval UV auroral distribution 2. The most poleward arc system and the dynamics of the magnetotail, J. Geophys. Res., 100, 12 093-12 102, 1995b.

Erickson, G. M., Substorm theories: are they converging?, Report of the GEM Workshop on the physics of the tail and substorms, Snowmass, Colorado, 1-2 July 1993, Ed. Hughes, W. J., Boston University, Boston, MA, USA, 1-18, 1993.

Erickson, G. M., and R. A. Wolf, Is steady state convection possible in the Earth's magnetotail?, Geophys. Res. Lett., 7, 897-900, 1980.

Erickson, G. M., R. W. Spiro, and R. A. Wolf, The physics of the Harang discontinuity, J. Geophys. Res., 96, 1633-1645, 1991.

Feldstein, Y. I., and Y. I. Galperin, The auroral luminosity structure in the high-latitude upper atmosphere: its dynamics and relationship to the large-scale structure of the Earth's magnetosphere, Rev. Geophys. Space Phys., 23, N 3, 217-275, 1985.

Frank, L. A., M. Ashour-Abdalla, J. Berchem, J. Raeder, W. R. Paterson, S. Kokubun, T. Yamamoto, R. P. Lepping, F. V. Coroniti, D. H. Fairfield, and K. L. Ackerson, Observations of plasmas and magnetic fields in Earth's distant magnetotail: comparison with a global MHD model, J. Geophys. Res., 100, 19 177-19 190, 1995.

Galperin, Y. I., Prebreakup arc morphology and the cross-tail line current model, in SUBSTORMS 1, Ed. Mattok, C., ESA SP335, Noordwijk, pp. 263-271, 1992.

Galperin, Y. I., Stable auroral arcs - observations and models, in SUBSTORMS 2, Eds.: Akasofu, S.-I. and J. Craven, University of Alaska Fairbanks, Fairbanks, USA, pp. 383-390, 1994.

Galperin, Y. I., Magnetospheric tail structure: concepts, problems, and storm-time development of the auroral oval, J. Atmos. Terr. Phys., 57, 1397-1414, 1995.

Galperin, Yu. I., Multiscale features of substorm onset, $S U B$ STORMS 4, Proc. 4-th International Conference on Substorms, March 1998, Ed. Kamide, Y., Nagoya University Press, Nagoya, 1998.

Galperin, Y. I., and Y. I. Feldstein, Auroral luminosity and its relationship to magnetospheric plasma domains, in Auroral Physics, Eds. Meng, C.-I., M. J. Rycroft, and L. A. Frank, Cambridge UK, Cambridge, pp. 207-222, 1991.

Galperin, Y. I., and Y. I. Feldstein, Mapping of the precipitation regions to the plasma sheet, J. Geomagn. Geoelectr., 48, 857$875,1996$.

Galperin, Y. I., and J. M. Bosqued, A new mechanism of substorm onset or local auroral activation, Cosmic Res, 36, 109-117, 1998.

Galperin, Y. I., J. Crasnier, Y. V. Lissakov, L. M. Nikolaenko, V. M. Sinitsin, J. A. Sauvaud, and V. L. Khalipov, Diffuse auroral zone, I. A model of the equatorial border of the auroral electron diffuse precipitation zone in the evening and near-midnight sectors, Cosmic Res (in Russian), 15, 421-434, 1977.

Galperin, Y. I., M. R. Ainbund, A. D. Boljunova, V. A. Gladyshev, L. S. Gorn, N. V. Jorjio, G. V. Khazanov, A. A. Klimashov, V. G. Kovalenko, R. A. Kovrazhkin, Y. V. Lissakov, B. V. Polenov, Y. N. Ponomarev, A. V. Shifrin, F. K. Shuiskaya, E. B. Usha, J. M. Bosqued and J. A. Sauvaud, Suprathermal plasma and energetic particle measurements aboard the AUREOL-3 satellite, Ann. Geophysicae., 38, N5, 583-590, 1982.

Galperin, Y. I., A. V. Volosevich, and L. M. Zelenyi, Pressure gradient structures in the tail neutral sheet as "Roots of the 
Arcs" with some effects of stochasticity, Geophys. Res. Lett., 19, 2163-2166, 1992.

Galperin, Y. I., V. S. Soloviev, K. Torkar, J. C. Foster, and M. V. Veselov, Predicting the plasmaspheric density radial profiles, $J$. Geophys. Res., 102, 2079-2091, 1997.

Galperin, Y. I., J. M. Bosqued, R. A. Kovrazhkin, and A. G. Yahnin, Stationary magnetospheric convection on November 24, 1981: 2. Small-scale structures in the dayside cusp/cleft, Ann. Geophysicae., 17, 375-388, 1999.

Grad, H., Some new variational properties of hydromagnetic equilibria, Phys. Fluids, 7, 1283-1292, 1964.

Hau, L. -N., Effects of steady state adiabatic convection on the configuration of the near-Earth plasma sheet, 2, J. Geophys. Res., 96, 5591-5596, 1991.

Hau, L. -N., R. A. Wolf, G. -H. Voigt, and C. C. Wu, Steady state magnetic field configurations for the Earth's magnetotail, $J$. Geophys. Res., 94, 1303-1316, 1989.

Heinemann, M., Representations of currents and magnetic fields in anisotropic magnetohydrostatic plasma, J. Geophys. Res., 95, 7789-7797, 1990.

Heinemann, M., and D. H. Pontius, Representation of currents and magnetic fields in anisotropic magnetohydrostatic plasma 2. General theory and examples, J. Geophys. Res., 96, 17 60517 626, 1991.

Hones, E. W., M. F. Thomsen, G. D. Reeves, L. A. Weiss, D. L McComas, and P. T. Newell, Observational determination of magnetic connectivity of the geosynchronous region of the magnetosphere to the auroral oval, J. Geophys. Res., 101, 26292640, 1996.

Kan, J. R., L. Zhu, and S. -I. Akasofu, A theory of substorm: onset and subsidence, J. Geophys. Res., 93, 5624-5640, 1988.

Kennel, C. F., Convection and substorms: paradigms of magnetospheric phenomenology, Oxford University Press, New York, 1995.

Kovrazhkin, R. A., J. M. Bosqued, L. M. Zelenyi, and N. V. Jorjio, Reconnection and plasma acceleration evidences manifestation at 0.5 million $\mathrm{km}$ distance in the Earth's magnetic tail, Letters to ZETP (in Russian), 45, 377-380, 1987.

Liu, W. W., B. -L. Xu, J. C. Samson, and G. Rostoker, Theory and observations of auroral substorms: a magnetohydrodynamic approach, J. Geophys. Res., 100, 79-95, 1995.

Lockwood, M., and S. W. H. Cowley, Ionospheric convection and the substorm cycle, in SUBSTORMS 1, Ed. Mattok, C., ESA SP-335, Noorwijk, pp. 83-88, 1992.

Lui, A. T. Y., Extended consideration of a synthesis model for magnetospheric substorms, in Magnetospheric Substorms, Geophys. Monograph 64, Eds. Kan, J. R., T. A. Potemra, S. Kokobun, and T. Iijima, AGU, Washington, D.C., 43, 1991a.

Lui, A. T. Y., A synthesis of magnetospheric substorm models, $J$. Geophys. Res., 96, 1849-1856, 1991 b.

Lyons, L. R., and J. C. Samson, Formation of the stable auroral arc that intensifies at substorm onset, Geophys. Res. Lett., 19, 21712174, 1992.

Nadubovich, Y. A., Thickness of band-like auroral forms, Geomagn. Aeron. (in Russian), 9, 87-93, 1969.

Nadubovich, Y. A., and G. V. Starkov, Fibrous structure of weak homogeneous auroral arcs, Geomagn. Aeron. (in Russian), 2, 71-73, 1962.

Newell, P. T., Y. I. Feldstein, Y. I. Galperin, and C.-I. Meng, The morphology of nightside precipitation, J. Geophys. Res., 101, $10737-10748,1996$.

Oguti, T., TV observations of auroral arcs, in Physics of Auroral Arc Formation, Eds. Akasofu, S.-I., and J. R. Kan, AGU, Geophys. Monogr. 25, Washington, pp. 31-41, 1981.

Onsager, T. G., and T. Mukai, Low altitude signature of the plasma sheet boundary layer: observations and model, Geophys. Res. Lett., 22, 855-858, 1995.

Peroomian, V., M. Ashour-Abdalla, and L. M. Zelenyi, The effect of non-adiabatic ions on the magnetotail's magnetic field, Eos Transactions $A G U, 78$ (46), Paper SM52D-07, 1997.
Pulkkinen, T. I., D. N. Baker, R. J. Pellinen, J. Buchner, H. Koskinen, R. E. Lopez, R. L. Dyson, and L. A. Frank, Particle scattering and current sheet stability in the geomagnetic tail during the substorm growth phase, J. Geophys. Res., 97, 19 283-19 297, 1992.

Pulkkinen, T. I., D. M. Baker, R. J. Pellinen, J. S. Murphree, and L. A. Frank, Mapping of the auroral oval and individual arcs during substorms, J. Geophys. Res., 100, 21 987-21 994, 1995.

Rothwell, P. L., L. P. Block, M. B. Silevitch, and C. -G. Falthammar, A new model for substorm onsets: the pre-breakup and triggering regimes, Geophys. Res. Lett., 15, 1279-1282, 1988.

Rothwell, P. L., M. B. Silevitch, L. P. Block, and C. -G. Falthammar, Prebreakup arcs: a comparison between theory and experiment, J. Geophys. Res., 96, 13 967-13 975, 1991.

Russell, C. T., The configuration of the magnetosphere, in Critical Problems of Magnetospheric Physics, Ed. Dyer, E. R., IUCSTP Secretariat c/o Nat. Acad. Sci., Washington, D.C., USA, 1-16, 1972.

Saito, Y., T. Mukai, M. Hirahara, S. Machida, and N. Kaya, Distribution function of precipitating ion beams with velocity dispersion observed near the poleward edge of the nightside auroral oval, Geophys. Res. Lett., 19, 2155-2158, 1992.

Samson, J. C., D. D. Wallis, T. J. Hughes, F. Creutzberg, J. M. Ruohoniemi, and R. A. Greenwald, Substorm intensifications and field line resonances in the magnetosphere, J. Geophys. Res., 97, 8495-8518, 1992.

Sergeev, V. A., W. Lennartson, R. J. Pellinen, and M. K. Vallinkoski, Average patterns of precipitation and plasma flow in the plasma sheet flux tubes during steady magnetospheric convection, Planet. Space Sci., 38, 355-363, 1990.

Sergeev, V. A., B. Aparicio, S. Perraut, M. V. Malkov, and R. J. Pellinen, Structure of the inner plasma sheet at midnight during steady magnetospheric convection, Planet. Space Sci., 39, 10831096, 1991.

Sergeev, V. A., T. I. Pulkkinen, R. J. Pellinen, and N. A. Tsyganenko, Hybrid state of the tail magnetic configuration during steady convection events, J. Geophys. Res., 99, 23 571$23582,1994$.

Sergeev, V. A., R. J. Pellinen, and T. I. Pulkkinen, Steady magnetospheric convection: A review of recent results, Space Sci. Rev., 75, 551-604, 1996.

Sivtseva, L. D., V. M. Filippov, V. L. Khalipov, A. E. Stepanov, and Y. I. Galperin, structure features of subauroral ionosphere from complex measurements on November, 24, 1981, in Polar geomagnetic disturbances and related phenomena, (in Russian), Eds. Raspopov, O. M. and V. V. Migulin, Kola Science Center, USSR Academy of Sciences, Apatity, USSR, pp. 11-15, 1989.

Trondsen, T. S., and L. L. Cogger, High resolution television observations of black aurora, J. Geophys. Res., 102, pp. 363378, 1997.

Tverskoy, B. A., Longitudinal currents in the magnetosphere, Geomagn. Aeron. (English translation), 22, 812-815, 1982a.

Tverskoy, B. A., Nature of homogeneous polar auroral arcs, Geomagn. Aeron. (English translation), 22, 794-799, 1982b.

Vasyliunas, V. M., Mathematical models of magnetospheric convection and its coupling to the ionosphere, in Particle and Fields in the Magnetosphere, Ed. B. M. McCormac, p. 60, D. Reidel, Hingham, Mass., 1990.

Yahnin, A. G., M. V. Malkov, V. A. Sergeev, R. J. Pellinen, O. Aulamo, S. Vennerstrom, E. Friis-Christensen, K. Lassen, C. Danielsen, J. D. Craven, C. Deehr, and L. A. Frank, Features of steady magnetospheric convection, J. Geophys. Res., 99, 40394051, 1994.

Zelenyi, L. M., R. A. Kovrazhkin, and J. M. Bosqued, Velocitydispersed ion beams in the nightside auroral zone: AUREOL-3 observations, J. Geophys. Res., 95, 12 119-12 139, 1990. 